Article

\title{
Impacts of the COVID-19 Lockdown Measures on the 2020 Columnar and Surface Air Pollution Parameters over South-Eastern Italy
}

\author{
Salvatore Romano*(D), Valentina Catanzaro and Fabio Paladini
}

check for

updates

Citation: Romano, S.; Catanzaro, V.; Paladini, F. Impacts of the COVID-19 Lockdown Measures on the 2020 Columnar and Surface Air Pollution Parameters over South-Eastern Italy. Atmosphere 2021, 12, 1366. https:// doi.org/10.3390/atmos12101366

Academic Editors: Ruixiong Zhang, Tzung May Fu, Deborah S. Gross and Andrey Khlystov

Received: 9 September 2021 Accepted: 17 October 2021 Published: 19 October 2021

Publisher's Note: MDPI stays neutral with regard to jurisdictional claims in published maps and institutional affiliations.

Copyright: (c) 2021 by the authors. Licensee MDPI, Basel, Switzerland. This article is an open access article distributed under the terms and conditions of the Creative Commons Attribution (CC BY) license (https:// creativecommons.org/licenses/by/ $4.0 /)$.
Department of Mathematics and Physics "E. De Giorgi", University of Salento, Via per Arnesano, 73100 Lecce, Italy; valentina.catanzaro@unisalento.it (V.C.); fabio.paladini@unisalento.it (F.P.)

* Correspondence: salvatore.romano@unisalento.it; Tel.: +39-0832297553

\begin{abstract}
The combined use of Lecce-University AERONET-photometer measurements and PM2.5, $\mathrm{PM} 10, \mathrm{NO}_{2}, \mathrm{CO}$, and $\mathrm{SO}_{2}$ concentrations from different sites of Apulia-Region Air-Quality Agency represents the peculiarity of this study, which evaluates the impact of COVID-19 lockdown (LD) measures on aerosol and gaseous pollutants. Monthly-averaged columnar and surface parameters of the 2020-year were compared with corresponding monthly parameters of the ref-year obtained by averaging 2017, 2018, and 2019 measurements in order to evaluate LD measure impacts by Average Percent Departure (APD\%). Photometer measurements showed that LD measures were likely responsible for the decrease in Aerosol Optical Depth (AOD). The APD\% estimated between the 2020- and ref-year AOD (at $440 \mathrm{~nm}$ ) was characterized by negative values from June to August, reaching the smallest mean value $(-46 \%)$ in June. Moreover, the columnar aerosol load appeared less affected by continental urban/industrial particles than previous years in the summer of 2020. The PM-concentration-APD\% calculated at ten sites was characterized by monthly trends similar to those of AOD-APD\%. PM-APD\% values varied from site to site and smaller values (up to $-57 \%$ in June) were on average detected at urban/suburban sites than at background sites (up to $-37 \%$ ). The impact of LD measures on gaseous pollutants was observed from the onset of LD.
\end{abstract}

Keywords: COVID-19; Aerosol Optical Depth; Ångström exponent; PM mass concentrations; gaseous pollutants

\section{Introduction}

The virus SARS-CoV-2 (Severe Acute Respiratory Syndrome Coronavirus 2) caused the COVID-19 (COrona VIrus Disease 2019) pandemic [1], which has been responsible for several million deaths across the world (https://covid19.who.int/; accessed on 22 July 2021). Lai et al. [2] have provided a comprehensive review on the potential mechanisms underlying the SARS-CoV-2 transmission exacerbated by background air pollutants. Therefore, various measures of lockdown (LD) and/or stay-at-home policies were issued in 2020 around the world by national and local governments to slow down the spread of the COVID-19 pandemic by trying to balance the safeguarding citizen's health and the negative LD impacts on economy. On 9 March 2020, Italy became the first European country to impose national lockdown measures to contain the spread of the SARS-CoV-2, restricting the movements of the population, except for necessity, work, and health. Further restrictive measures were adopted on 11 March 2020, concerning the suspension of retail commercial activities, catering services, and personal service activities; on 22 March 2020 came the suspension of most industrial and commercial activities and the prohibition to leave the residence municipalities, except for proven work needs, absolute urgency, and health reasons. Some of the restrictive measures started being removed from 4 May 2020 onward. The reopening of commercial activities and intra-regional mobility was allowed to begin from 18 May 2020. 
Since human activities decreased because of the prevention and control measures during the lockdown, several studies have been undertaken and are still carried out around the world to investigate the possible changes in aerosol pollution because of the COVID-19 lockdown measures (e.g., [3-6]). Venter et al. [7] have shown that the global response to the COVID-19 pandemic resulted in unprecedented reductions in economic activity, and that lockdown events reduced the population-weighted concentration of nitrogen dioxide and particulate matter levels by about $60 \%$ and $31 \%$, respectively, in 34 countries. Reductions in transportation sector emissions were largely responsible for $\mathrm{NO}_{2}$ anomalies. Gkatzelis et al. [8] provided a critical review of the global impact of COVID-19 lockdown measures on air quality, in addition to some recommendations.

The first confirmed Italian case of infection by SARS-CoV-2 was detected at the end of February in southern Lombardy, which is characterized by very large urban areas and represents one of the most polluted areas of Europe due to its unfavourable geographical position, climate characteristic, land use, and emission sources. Lonati and Riva [9] assessed $\mathrm{NO}_{2}$ and benzene reductions in the $-40 \%$ to $-35 \%$ range compared with the previous years in the Po Valley of Northern Italy, concluding that this was because of the corresponding reductions in the emissions from road traffic. Air quality improved in all of the countries in which strict lockdown measures were adopted, in contrast to the detrimental social and economic effects (e.g., [10-16]). Sulaymon et al. [17] have investigated the relationships between different air pollutants and meteorological variables before, during, and after lockdown measures in Wuhan (China), which represented the Chinese city with the first confirmed cluster of COVID-19 cases. Moreover, Albayati et al. [18] have reported a comprehensive summary of the main effects of the COVID-19 lockdown measures on air pollution in different countries (India, China, United States, Italy, Brazil, and Malaysia). Arregoces et al. [12] reported a review of the 2020 studies on the impact on air quality during the COVID-19 pandemic (Table 1 of their work). Another review of the lockdown impacts on the air quality has been provided by Skiriene and Stasiskiene [19]; they have estimated that the reduction in $\mathrm{NO}_{2}, \mathrm{PM} 2.5$, and PM10 was approximately in the range of $20-40 \%$, analysing data from 5 different European countries (England, Italy, Spain, France, and Sweden). Munir et al. [20] compared three different approaches to assess their performance, using both estimated and measured air quality and meteorology data from several air quality monitoring stations in Reading (England). They found that changes in pollutant concentrations varied both in space and in time according to the adopted approach, the type of monitoring site and the data type. The comparison with the same period in previous years before the pandemic reported by Cao et al. [3] has shown that the aerosol pollution, especially PM2.5, significantly decreased, the aerosol reduction in areas with high air pollution was more obvious, and the levels of PM2.5 were more sensitive to emission reductions than PM10. In contrast, other studies showed no significant changes in particulate matter (PM2.5 and PM10) mass concentrations over Northern Italy, according to [21], indicating that the lockdown effects on the air quality can be strictly site-dependent. In addition to surface-monitored air quality parameters, several studies also focused on remote sensed data from surface- and/or satellite-based devices [22-26]. Campanelli et al. [22] investigated the COVID-19 lockdown effects on the atmospheric composition in five Italian urban sites by using data collected from 1 January to 31 May 2020. These data were related to meteorological conditions which identify the long-range transport events. They found that the impact on the Aerosol Optical Depths (AOD), PM, and gaseous pollutant concentrations varied from site to site. Therefore, the analysis of the LD measure impacts on pollution at different sites deserves attention; moreover, most of the previous studies focused on the LD impacts up to April and/or May 2020. 
Table 1. Corresponding time intervals and number of days for the three selected periods Pre-LD, LD (lockdown), and Post-LD.

\begin{tabular}{ccc}
\hline Period & Time Interval & Number of Days \\
\hline Pre-LD & 1 January-8 March 2020 & 68 \\
LD & 9 March-17 May 2020 & 69 \\
Post-LD & 18 May-26 July 2020 & 69 \\
\hline
\end{tabular}

The COVID-19 lockdown (LD) measure impacts both on columnar and on surface air pollution parameters have been investigated in this study over south-eastern Italy. More specifically, measurements from the "Lecce University" sun/sky photometer operating within the AErosol RObotic NETwork (AERONET) have been used to evaluate the LD measure impact on columnar aerosol properties. In contrast, ground-based air quality measurements from ten different monitoring stations of the Apulia-Region Air Quality Agency (ARPA-Puglia) have been used to evaluate $\mathrm{LD}$ impacts on PM2.5, PM10, $\mathrm{NO}_{2}, \mathrm{CO}$, and $\mathrm{SO}_{2}$ concentrations. It is commonly assumed that ground-level aerosol properties are mainly determined by local meteorology and sources of pollution, while aloft aerosol particles are also strongly affected by long-range transboundary air pollution because atmospheric particles are generally lifted to high altitudes before being transported over long distances. South-eastern Italy is a narrow and flat peninsula in the central Mediterranean basin, whose aerosol particles are significantly affected by long-range transported air masses from the surrounding countries either at the surface and along the aerosol column, as shown in several studies (e.g., $[27,28]$ ). Therefore, considering the relevant long-range transport of aerosol particles over south-eastern Italy, column-integrated aerosol parameters and surface PM properties were likely affected by the impacts of the lockdown measures issued in 2020 around different European countries.

The analysis of the relationships between surface and column-integrated aerosol parameters represents one of the novel investigations of this study, which have been examined in rather few studies to the best of our knowledge. Note also that measurements performed throughout the whole year of 2020 have been compared with the corresponding mean values of the years 2017, 2018, and 2019 (selected as reference years) to investigate how long the LD measure effects lasted after the removal of the restrictive measures: this represents the main novel contribution of this study. Particular attention has also been paid to the comparison between data retrieved from measurements performed before, during, and after the LD measures. Moreover, LD measure impacts on PM mass concentration have been investigated at 10 sites within a monitoring area less than $50 \mathrm{~km}$ wide, to investigate how LD measure impacts on pollution varied between sites few $\mathrm{kms}$ away but with different features (i.e., urban, suburban, industrial or background site). Therefore, besides evaluating the effective impact of the human activities on the columnar aerosol properties and surface pollutants, the analysis of their relationships could contribute to the development of new procedures for the management and control of the air quality.

\section{Experimental and Methodology}

\subsection{Study Area, Analysed Time Intervals, and Statistical Analyses}

Figure 1 shows the study area, which is located in a narrow and flat peninsula of south-eastern Italy, distant from large pollution sources, less than $100 \mathrm{~km}$ away from the Balkan and Greek coast and about $700 \mathrm{~km}$ away from the Africa coast. The locations of the 10 selected monitoring sites (Sites 1-10) of the Apulia-Region Air Quality Agency (ARPA Puglia; https: / /www.arpa.puglia.it/, accessed on 10 October 2021) are shown in the insert of Figure 1, in addition to the AERONET sun/sky photometer site at the Mathematics and Physics Department of the University of Salento in Lecce (Site 11). A characterization of the mean aerosol properties and meteorological conditions at the study area has been provided in previous works [28-30]. 


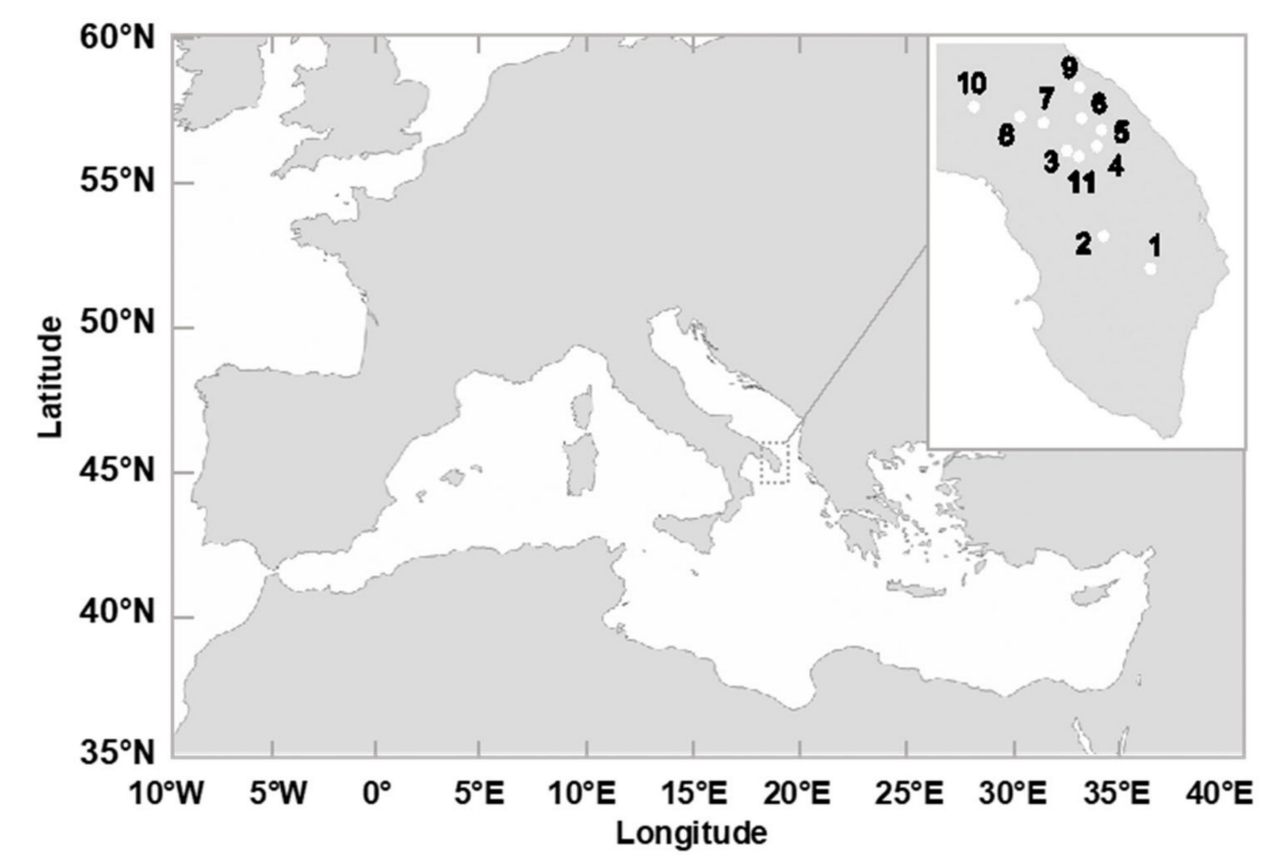

Figure 1. The map illustrates the geographical location of the study area in south-eastern Italy, in the Central Mediterranean basin. The location of the monitoring stations of the Apulia Region Air Quality Agency (ARPA Puglia) considered in this study (Maglie 1, Galatina 2, Arnesano 3, Lecce-Libertini 4, Lecce-Garigliano 5, Surbo 6, Campi Salentina 7, Guagnano 8, Cerrate 9, and San Pancrazio 10) is also reported in the insert, in addition to the AERONET photometer site at the Department of Mathematics and Physics of the University of Salento in Lecce (11).

The Italian COVID-19 lockdown lasted 10 weeks from 9 March to 17 May 2020. Therefore, columnar and surface air pollution parameters of the 68 days prior to the lockdown start time (Pre-LD days; 1 January-8 March 2020) and of the 69 days following the lockdown end (Post-LD days; 18 May-26 July 2020) have firstly been compared to those of the 69 lockdown (LD) days, to obtain a first estimate of the lockdown impact on the investigated parameters (Table 1). Firstly, the statistics of Pre-LD, LD, and Post-LD periods have been compared estimating the respective mean values and the 5th, 25th, 50th, 75th, and 95th percentiles of each tested parameter that have been represented by box plots. Then, we have defined a so-called reference year (ref-year) based on measurements performed in the years 2017, 2018, and 2019, according to the selection performed in other studies $[31,32]$. In more detail, the daily mean values of each tested parameter referring to each of these three years have been averaged to calculate the corresponding monthly mean values of the ref-year. The monthly means of each parameter have been computed as a good compromise between temporal resolution and statistical robustness of the data to be compared. We believe that day-by-day comparisons may not be significant, since both pollution and meteorological impacts may significantly vary day-by-day in each year. We also believe that meteorology impacts on pollution are embedded in the ref-year dataset.

The monthly evolution of each ref-year parameter has been compared with the corresponding one of the year 2020 to evaluate by box plots and statistical analyses the COVID-19 impact throughout that year. The average percent departure (APD\%) for selected time intervals was also calculated to quantify the lockdown impact both on columnar and on surface air pollution parameters throughout the year 2020:

$$
\mathrm{APD} \%=\left[\left(\text { Data }_{2020}-\text { Data }_{\text {ref }}\right) / \text { Data }_{\text {ref }}\right] \times 100
$$

where Data $_{2020}$ and Data ${ }_{\text {ref }}$ represent the selected parameters of the 2020 and ref-year, respectively.

Since we have proved that not all the analysed datasets were normally distributed based on the Kolmogorov-Smirnov test, non-parametric statistical methods were used to 
test if significant differences were present among parameters referring to different time intervals. More specifically, the comparison among the Pre-LD, LD, and Post-LD datasets for each columnar and surface analysed parameter was performed by the Kruskal-Wallis One Way Analysis Of Variance on Ranks. This test was then followed by the Dunn's test, which was used to identify which pair of samples significantly differed by testing the difference in the sum of the related ranks, with an overall confidence level greater than $95 \%$ [33,34]. On the contrary, the Mann-Whitney test was used to identify the statistically significant differences between the 2020 and the ref-year datasets. A similar procedure of statistical analyses on air pollutants has also been conducted in previous studies $[17,35]$.

\subsection{Columnar Aerosol Parameters}

The AERONET sun/sky photometer denoted as "Lecce University" is located on the roof of the Mathematics and Physics Department of the University of Salento (Site 11 in the insert of Figure 1), where it has been operating since May 2003. AERONET is an international federation of ground-based sun/sky photometers established by NASA (e.g., [36,37]). The data reported in this study were downloaded on 26 April 2021 and are based on Version 3, Level 1.5 daily solar data of the years 2017, 2018, 2019, and 2020. The Aerosol Optical Depth (AOD) at the 440 and $870 \mathrm{~nm}$ wavelengths was used as extensive parameter. Then, the Ångström exponent $(\AA)$ and the Ångström exponent difference $(\Delta \AA)$ were calculated as intensive parameters. The column-integrated Ångström exponent describes the spectral dependence of the AOD and at the $440-870 \mathrm{~nm}$ wavelength pair it is given by:

$$
\AA(440 \mathrm{~nm}, 870 \mathrm{~nm})=-\ln [\mathrm{AOD}(440 \mathrm{~nm}) / \operatorname{AOD}(870 \mathrm{~nm})] / \ln (440 / 870)
$$

$\AA$ (440 nm, $870 \mathrm{~nm})$ is commonly adopted by the users of AERONET data as a qualitative indicator of the particle size: the smaller the particle size, the larger the $\AA$ value. In general, $\AA<1$ and $\AA>1$ represent populations dominated by coarse and fine mode particles, respectively. However, $\AA$ alone does not provide unambiguous information on the relative weight of coarse and fine mode particles if the particles are characterized by a bimodal/multimodal size distribution, according to [38]. Fine mode particles can have the same $\AA$ as mixtures of coarse and fine mode particles and some authors (e.g., [38-40]) have demonstrated that $\triangle \AA$ can provide more information on the relative contribution of fine and coarse mode particles, where:

$$
\Delta \AA=\AA(440 \mathrm{~nm}, 675 \mathrm{~nm})-\AA(675 \mathrm{~nm}, 870 \mathrm{~nm})
$$

Negative $\triangle \AA$ values are representative of size distributions with dominant fine particle contributions [38]. $\Delta \AA$ increases with the contribution of the coarse particle contributions as shown by $[29,41]$ for the study site, where bi-modal or multi-modal particle size distributions are generally prevailing.

\subsection{Surface Air Pollution Parameters: $\mathrm{PM} 2.5, \mathrm{PM}_{10}, \mathrm{NO}_{2}, \mathrm{CO}$, and $\mathrm{SO}_{2}$}

Mass concentrations of some air pollutants as PM2.5, PM10, $\mathrm{NO}_{2}, \mathrm{CO}$, and $\mathrm{SO}_{2}$ have been used to evaluate the LD impact on air pollution at the surface. Table S1 lists the ten selected monitoring sites of ARPA Puglia, shown in the insert of Figure 1, with the corresponding monitored pollutants and monitoring area type. Note that all the air pollutant concentrations are regularly a priori quality controlled according to the Directive CEN $\backslash$ TS 16450:2013, which defines a criterion of valid data for daily means as at least 75\% of the data availability within a day. Five, three, and two monitoring sites are located in suburban, urban, and rural areas, respectively. Sites 9 and 10 are background monitoring sites according to ARPA Puglia (https: / / www.arpa.puglia.it/, accessed on 10 October 2021). Nitrogen dioxide $\left(\mathrm{NO}_{2}\right)$, carbon monoxide $(\mathrm{CO})$, and sulphur dioxide $\left(\mathrm{SO}_{2}\right)$ are the main gaseous pollutants monitored by ARPA Puglia. However, only some of the mentioned gaseous pollutants are monitored at each monitoring site, as shown in Table S1. The 
PM2.5/PM10 and $\mathrm{NO}_{2} / \mathrm{CO}$ ratios have likely been used to distinguish between potential emission sources.

\section{Results and Discussion}

The LD measure impacts on columnar aerosol optical parameters and PM mass concentrations at the surface are firstly analysed, followed by their relationships. Then, the $\mathrm{LD}$ measure impacts on $\mathrm{NO}_{2}, \mathrm{CO}$, and $\mathrm{SO}_{2}$ mass concentrations have been investigated.

\subsection{Changes in Columnar Aerosol Parameters before, during, and after the Lockdown}

Figure S1a shows the time series of the AOD daily means both at 440 and at $870 \mathrm{~nm}$ from 1 January to 26 July 2020, covering the Pre-LD, LD, and Post-LD time intervals. Discontinuities in the time series are due to meteorological (cloudy and/or rainy days) or technical reasons. The variability range of the AOD daily means (both at 440 and at $870 \mathrm{~nm}$ ) decreased in the Post-LD period (Figure 2a). In particular, Figure 2a shows that both mean and median values of the AOD at $440 \mathrm{~nm}$ in the Pre-LD period are slightly smaller than the LD ones. Accordingly, as summarized in Table S2, Dunn's test results show for the AOD at $440 \mathrm{~nm}$ that Pre-LD and LD data are the only statistical different, while only Pre-LD and Post-LD data are statistically different in the case of AOD at $870 \mathrm{~nm}$, highlighting a slightly different impact of the lockdown measures at different AOD wavelengths $\lambda$. Note that $A O D$ values mainly decrease with $\lambda$ when fine particles are prevailing. The time series of the daily-averaged intensive parameters $\AA$ and $\triangle \AA$ displayed in Figure $S 1 b, c$, respectively, show that both parameters on average increased with time from Pre-LD to Post-LD periods, as it is also clearly shown by the $\AA$ and $\Delta \AA$ box plots in Figures $2 b, c$, respectively. The Dunn's test results displayed in Table S2 show that only the Pre-LD/Post-LD pair was statistically different in the case of $\AA$, while both the Pre-LD/Post-LD and the LD/Post-LD pairs were statistically different for $\Delta \AA$. As mentioned, $\AA$ and $\Delta \AA$ are intensive parameters and their values change with the column-based size distribution of atmospheric aerosols (e.g., [38,40]). In particular, for bimodal size distributions, the combined temporal increase in $\AA$ and $\Delta \AA$ values may be associated with the decrease in the fine mode particle radius, as shown by $[29,42]$ at the study site. The decrease in the anthropogenic activities (e.g., traffic, industry, and coal-burning emissions) and, consequently, of air pollutant emissions since the LD starting time have likely been responsible for the decrease in the secondary particle formation in the atmosphere and for the shift of the fine mode particle radius toward lower values. On average, secondary particles contribute to accumulation mode particles [43]. Air pollution events tend to occur when condensation processes produce significant number concentrations of accumulation-mode particles [44]. Martins et al. [45] measured aerosol size distributions in the ultrafine particle range at the Metropolitan Area of São Paulo (Brazil) during a transition period between a highly polluted episode and a clean one. They found particles distributed in the nucleation and Aitken mode during the clean period and particles with larger geometric mean diameters during polluted periods. Analogously, Monteiro dos Santos et al. [46] also found a strong increase in accumulation mode particles with the larger presence of secondary species such as organics and sulphates. Analysing $\AA$ and volume size distribution data from the AERONET photometer, Sannino et al. [47] found at Naples (Italy) a reduction in the column-based coarse-mode aerosol component during the lockdown, according to our results (Figure $2 b, c)$. They explained this reduction as likely associated with the decrease in particulate produced by vehicular traffic and anthropogenic activities. Shukla et al. [48] found an opposite result from AERONET sun/sky photometer measurements in Kanpur (India). Due to the restricted anthropic activities during lockdown, they found that fine mode particle contributions decreased, while coarse-mode particles were predominant during the LD. Pre-LD and Post-LD periods were characterized by fine particles with slightly absorbing properties. Therefore, lockdown measure effects on columnar aerosol properties are strictly site-dependent because of the highly variable aerosol types/sources and the long-range pollution impacts. LD measures were applied to several European countries in the 2020 
spring-summer (SS) months. Consequently, the main properties of the long-range transported air masses from these countries were also likely affected by the LD measures with a potential effect particularly on the columnar aerosol properties. In conclusion, at the study site LD measures have likely been responsible for the weak AOD increase from the LD to the Post-LD period and the increase in both the $\AA$ and $\Delta \AA$ mean values. We must be aware that meteorological parameter and aerosol particle variations from winter (Pre-LD) to summer (Post-LD) have also likely contributed to the observed LD impacts. An accurate analysis on the potential effects of the seasonal meteorological variations on the columnar aerosol properties at the study site were reported in [28].
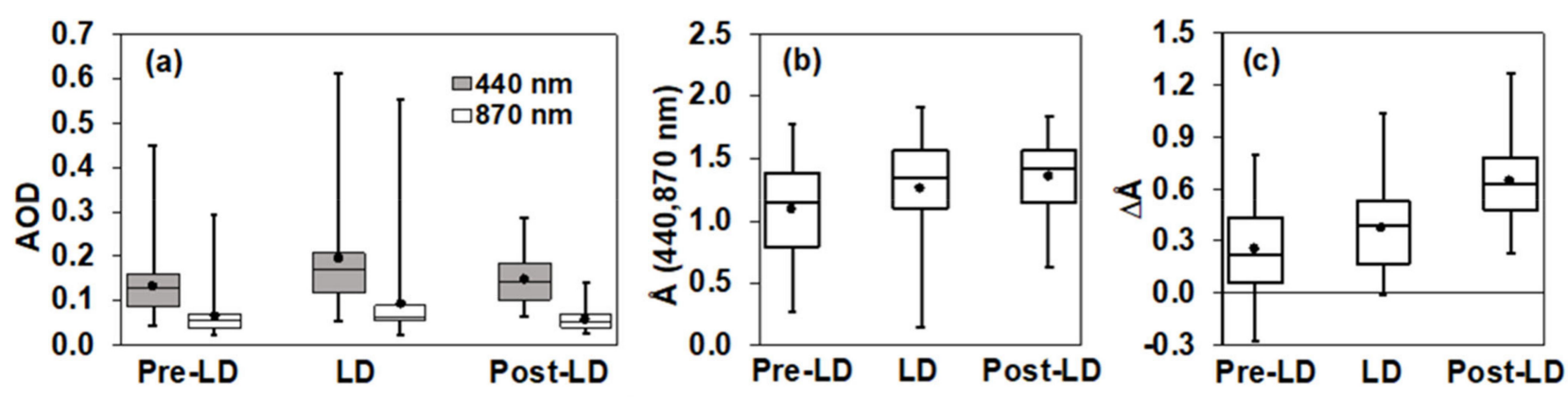

Figure 2. Box plots of the (a) Aerosol Optical Depth AOD at $440 \mathrm{~nm}$ (grey boxes) and $870 \mathrm{~nm}$ (white boxes), (b) Ångström Exponent $\AA$ at the wavelength pair 440-870 nm, and (c) Ångström Exponent difference $\triangle \AA$ in Pre-LD (before lockdown), LD (during lockdown), and Post-LD (after lockdown) periods. Horizontal lines and dots in each box are the median and mean values, respectively. The 25th and the 75th percentiles are indicated by the lower and upper boundaries of the box, respectively. The lower and upper whiskers represent the 5th and the 95th percentiles, respectively.

3.1.1. Columnar Optical Parameter throughout the Year 2020 and Comparison with the Corresponding Ref-Year Data

Columnar aerosol properties are season-dependent at the study site $[28,29,49,50]$. Therefore, a proper estimate of the LD measure's impact can likely be obtained by comparing aerosol parameters of selected time intervals of the year 2020 with the averaged ones of previous years. In particular, the 2020 AOD, $\AA$, and $\Delta \AA$ time series have been compared with the corresponding ones of the so-called reference year (ref-year) to better evaluate the LD restriction's impacts, which were calculated by averaging corresponding daily mean values of the years 2017, 2018, and 2019. Figure S2 provides an overview of the comparison between the AOD (440 nm) daily means retrieved at the study site in 2020 and the corresponding ones of (a) 2017, (b) 2018, and (c) 2019 to show the AERONET data availability from 2017 to 2020. The lack of data points, which varied from year-to-year, was due to meteorological (cloudy and/or rainy days) and/or technical reasons. Figure S3 compares by box plots the monthly time series of (a) AOD (440 nm), (b) $\AA$, and (c) $\Delta \AA$ of the 2020- and the ref-year, highlighting that both ref- and 2020-AOD monthly mean and median values on average increased in summer, as commonly observed all over the Mediterranean basin because of the lack of rainy days and the prevailing stagnant atmospheric conditions that favour the accumulation of atmospheric particles. Moreover, the large solar irradiance, which favours the secondary particle formation, likely contributed to the summer AOD increase at the study site (e.g., [28]). Figure S3a shows that the AOD increase in June, July, and August was smaller in 2020 than in the corresponding one of the ref-year. This last result is likely to be strictly related to the lockdown measures and/or the stay-at-home policies issued in 2020 in Italy and in other countries, which determined the decrease in anthropogenic activities and, hence, in air pollutant emissions since March/April. Figure S3b,c suggest that the $2020 \AA$ and $\Delta \AA$ values were also affected by the LD measures. In particular, Figure S3c shows that the $\Delta \AA$ rate of increase in June, July, and August 2020 was greater than the corresponding one of the ref-year. The Mann-Whitney test was used to identify the significant monthly differences between the 2020 and the 
ref-year dataset. Main results are summarized in Table S3, which shows that June, July, and August AOD and $\Delta \AA$ values of the 2020 were all statistically different (at p-level $\leq 0.001$ ) from the corresponding values of the ref-year. $\AA$ values were statistically different (at p-level $\leq 0.05$ ) only in June and July. These results might indicate that the columnar aerosol parameters were significantly affected by the LD measures mainly since June 2020, when most of the restrictive measures were removed in Italy and likely in most European countries. The LD impact on columnar aerosol parameters lasted several months from the removal of LD measures, likely because most of the atmospheric particles were not directly emitted in the atmosphere, as on the contrary is the case for gaseous pollutants [9,21]. In fact, atmospheric particles may also be formed by coagulation, mixing, and secondary processes, which in turn depend on the particle residence time in the atmosphere. The monthly AOD, $\AA$, and $\triangle \AA$ APD\% (Figure 3 ) was calculated according to Equation (1), from the monthly time series of the 2020- and ref-year datasets, to quantify the percentage changes of each tested parameter. Figure S4 provides the monthly AOD APD\% calculated from the AOD time series of the years (a) 2017 and 2020, (b) 2018 and 2020, and (c) 2019 and 2020, from which the AOD APD\% shown in Figure 3 a was calculated. We believe that Figure 3 can likely indicate that the APD\% changes in June, July, and August were mainly due to LD measures, which have likely been responsible in June for the $-46 \%$ and $-14 \%$ decrease in the AOD and $\AA$, respectively, and the $110 \% \Delta \AA$ increase in August, because of the changes of the columnar aerosol load and their microphysical properties. We must be aware that dust events and forest fires occurring in summer over the Mediterranean basin may affect the year-by-year variability of columnar aerosol properties up to autumn if the stagnant atmospheric conditions persist, whose impacts, we believe, are embedded in the spring-summer monthly means of both the ref- and the 2020-year. Sannino et al. [47] highlighted the 2020 combined effect of Saharan dust intrusions and LD measures on columnar aerosol properties at Naples (Italy) studying the variations between Pre-LD and LD periods both in presence and in absence of desert dust.
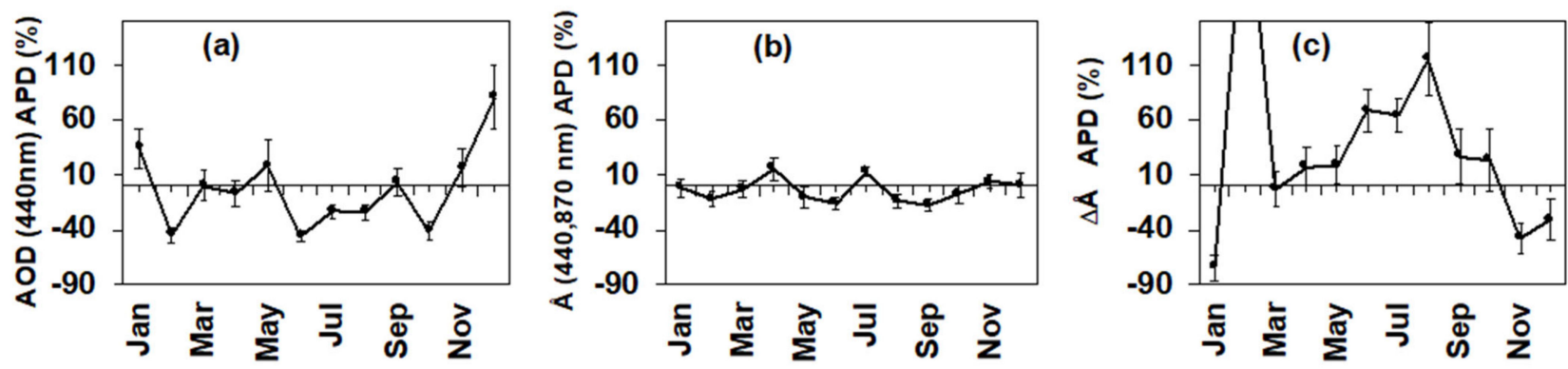

Figure 3. Time series of monthly average percent departure (APD\%) in the year 2020 with respect to the reference years (2017, 2018, and 2019) for (a) Aerosol Optical Depth AOD at 440 nm, (b) Ångström Exponent $\AA$ at the wavelength pair $440-870 \mathrm{~nm}$, and (c) Ångström Exponent difference $\Delta \AA$. Error bars represent the corresponding uncertainty estimated by the propagation of error on the APD\%.

$\AA$ versus AOD scatterplots are commonly used to obtain a qualitative graphical indication on the aerosol load due to particles of different size and type, since they tend to concentrate in different areas of the plot, and this can enable the inference of particles from different sources [51]. In this study, $\AA$-AOD scatterplots referring to measurements performed in 2020 have been compared with the corresponding ones of the ref-year to infer the main differences on the probable particle sources. Figure 4 shows the $\AA$ versus AOD scatterplot referring to (a) June, (b) July, and (c) August 2020, colour-coded by the $\Delta \AA$ values. Corresponding plots referring to ref-year June, July, and August are then shown in Figure $4 \mathrm{~d}-\mathrm{f}$, respectively. Santese et al. [52] used a graphical mask to classify aerosols of different type by the $\AA$-AOD scatterplot at the study site. It was assumed that marine particles were characterized by the data points with $\mathrm{AOD}<0.15$ and $\AA \leq 1.6$, according to [53]. Data points characterized by both $\mathrm{AOD} \geq 0.15$ and $\AA \leq 0.9$ were considered 
representative of desert dust, while all the other data were considered representative of continental urban/industrial particles. Figure 4 a shows that most of the $\AA$-AOD data points were characterized by AOD $<0.15$ and $\AA \leq 1.6$ in June 2020 and, therefore, they were likely associated with marine particles. In contrast, Figure $4 \mathrm{~d}$ shows that most of the June-ref-year $\AA$-AOD data points were characterized by AOD $>0.15$ and $\AA>0.9$, thus likely associated with continental urban/industrial particles. Similar deductions can be obtained by comparing Figure $4 b, c$ with Figure $4 \mathrm{e}, \mathrm{f}$. Therefore, the results illustrated in Figure 4 have likely indicated that the columnar aerosol load in June, July, and August 2020 was less affected by continental urban/industrial particles than previous years, likely because of the LD measures over Italy. Being columnar aerosol properties also affected by long-range transported air masses, LD impacts on some European countries may have contributed to Figures 3 and 4 outcomes. To this end, note that during the first period of COVID-19 lockdowns in Europe, solid fuel for residential heating is believed to have been an important source of primary aerosols in many regions, because individuals stayed more at home than in previous years.
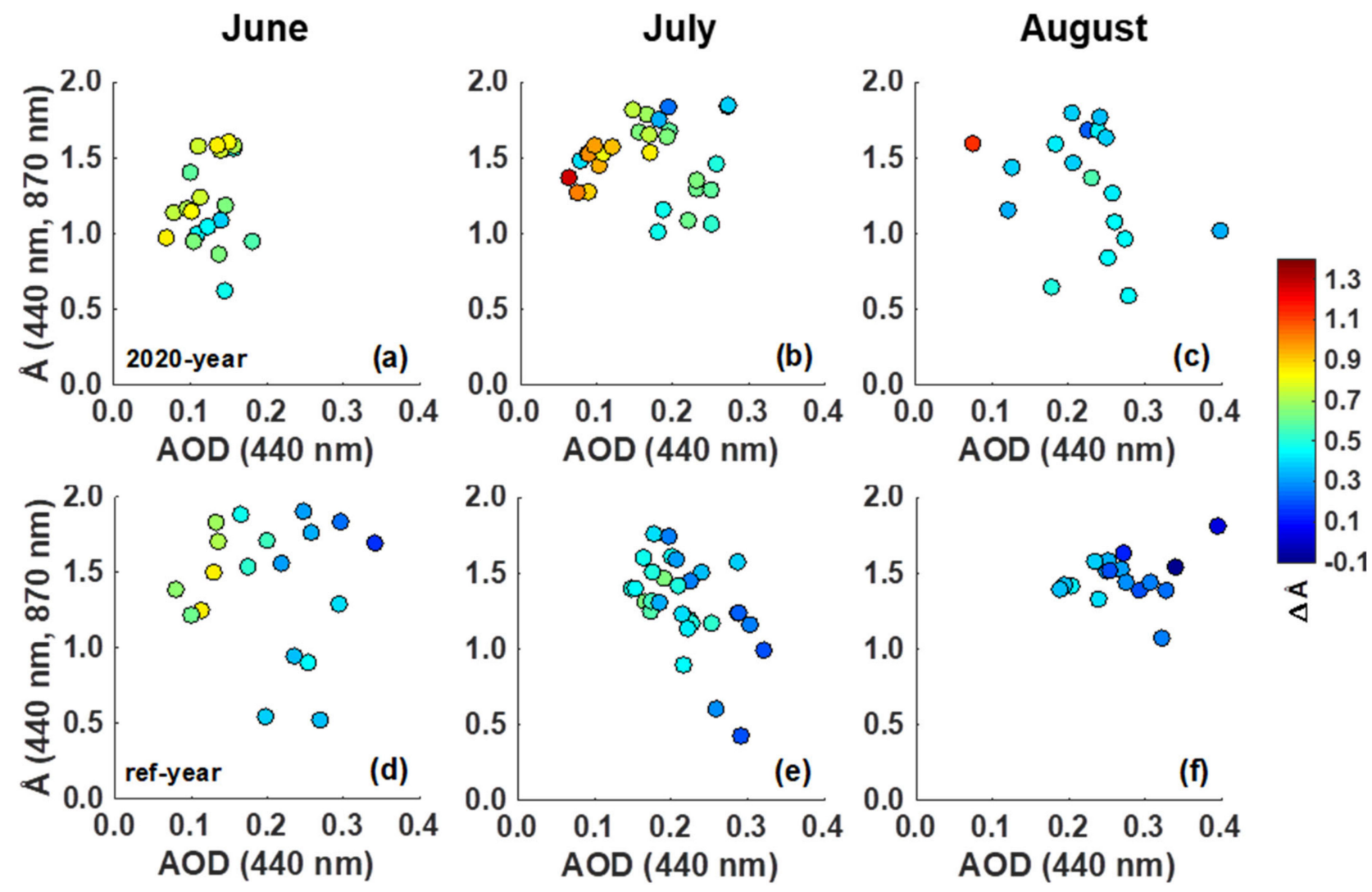

Figure 4. Scatterplot of Ångström Exponent $\AA$ at the wavelength pair 440-870 nm as a function of Aerosol Optical Depth

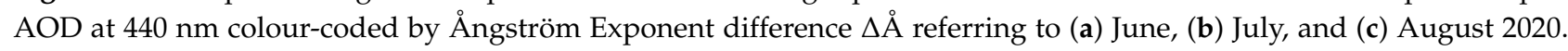
Corresponding scatterplots referring to ref-year (2017, 2018, and 2019) June, July, and August are shown in (d-f), respectively.

\subsection{PM Mass Concentrations before, during, and after the Lockdown}

The impacts of the LD measures on the ground-based PM mass concentration monitored at 10 sites of south-eastern Italy (Table S1) are analysed in this section. Figure S5a,c,e show, as an example, both PM2.5 and PM10 mass concentration time series at Sites 4, 7, and 9, respectively, during the Pre-LD, LD, and Post-LD days. The three sites have been selected because they are located in areas differently affected by pollution, as indicated in Table S1. Site 4 (Lecce-Libertini) is in an urban area affected by traffic, Site 7 (Campi Salentina) is located in a suburban area, while Site 9 (Cerrate) is in a rural-background site close to the Adriatic Sea (Figure 1). The PM2.5 and/or PM10 time series referring to 
the other 7 sites (Figure 1) are in Figure S6. Discontinuities in the time series are due to technical reasons. Figures S5 and S6 show that PM2.5 and PM10 mass concentrations were characterized by similar trends at most of the monitoring sites: both PM2.5 and PM10 daily means on average decreased with time after the start time of the LD, highlighting the LD measure impact on both PM fractions.

The time series of the PM2.5/PM10 mass ratios and the (PM10-PM2.5) mass concentrations are also shown in Figure S5b,d,f for Sites 4, 7, and 9, respectively. Mass concentrations of coarse particles (PM10-PM2.5) appear less affected by the LD measures, probably because the natural sources that are generally responsible for their emission were less affected by the LD measures. The PM2.5/PM10 mass ratios, which on average decreased after the LD start, suggest that the LD measures were likely responsible for a smaller decrease in the PM10 mass concentration than that due to PM2.5 particles. PM2.5 particles, which are mostly due to the anthropogenic activities, were likely more affected by the LD measures. Cao et al. [3] also found that the PM2.5 levels were on average more sensitive to emission reductions than PM10 in different world regions, according to our findings.

PM10, PM2.5, PM2.5/PM10, and (PM10-PM2.5) box plots referring to the Pre-LD, LD, and Post-LD days at Sites 4, 7, and 9 are shown in Figure 5. Figure S7 provides the corresponding box plots referring to the other 7 monitoring sites. Figures 5 and S7 highlight that the PM changes were strictly associated with the monitoring area/type (Table S1), with larger PM reductions in urban and suburban sites and not-significant PM variations in rural background sites. More specifically, considering the urban/suburban sites represented in Figure 5, PM2.5 and PM10 mean mass concentrations decreased from the Pre-LD to the Post-LD period by 40 and 30\%, respectively, at Site 4, and by 68 and $50 \%$, respectively, at Site 7, likely because of the decrease in the anthropogenic activities determined by the LD measures. Conversely, PM2.5 and PM10 mean mass concentrations decreased to a lesser extent (by 26 and 11\%, respectively) from the Pre-LD to the Post-LD period at Site 9 (Cerrate), which is a background monitoring site weakly affected by local anthropogenic activities and in turn less affected by LD measures. The Kruskal-Wallis and the Dunn's tests shown in Table S4 support our comments. The LD measure effects on the PM10 and PM2.5 concentrations were highly site-dependent, according to previous studies, either because each site has its own specific characteristics (e.g., type, meteorology, anthropogenic activities) or because of the different LD measures adopted by the different countries. Monitoring stations in urban sites such as Milan [54], Florence [13], Athens [55], Barcelona [56], and Baghdad [57] experienced a significant PM decrease due to the LD measures, since the PM pollution was strictly related to the anthropogenic activities at these sites, as we found at Sites 4 and 7. Conversely, other studies reported PM concentration increases during the LD periods, as summarized by [58]. In particular, they estimated a PM10 and PM2.5 positive gain during lockdown ranging from $21.96 \%$ to $62.00 \%$ and from $36.24 \%$ to $80.31 \%$, respectively, analysing measurements performed in Leeds, Sheffield, and Manchester (England). They explained that the increase in PM levels during the COVID-19 LD was likely associated with seasonal variations, and that it would have been even higher in absence of the LD.

The LD impacts on the PM2.5/PM10 mass ratio and on the coarse-mode fraction (PM10-PM2.5) at Sites 4, 7, and 9 are shown by box plots in Figure $5 c, d$, respectively. The mean PM2.5/PM10 mass ratio decreased since the LD measure start time (Figure 5c) and was stronger at the suburban Site 7. In more detail, PM2.5/PM10 mass ratio of Site 7 presented a significant difference among all the 3 studied periods, according to the Dunn's test (Table S4), confirming the results reported in [3]. The background Site 9 was less affected by the human activity reductions due to the LD measures and, consequently, the PM2.5/PM10 mass ratio did not present any significant difference between the Pre-LD and LD periods, in addition to PM2.5, PM10, and (PM10-PM2.5) mass concentrations. Any marked impact of the LD measures on (PM10-PM2.5) mass concentrations was observed mainly between the LD and Post-LD periods as Figure $5 \mathrm{~d}$ and Table $\mathrm{S} 4$ show, since coarse particles were weakly affected by anthropogenic activities at the tested sites. 

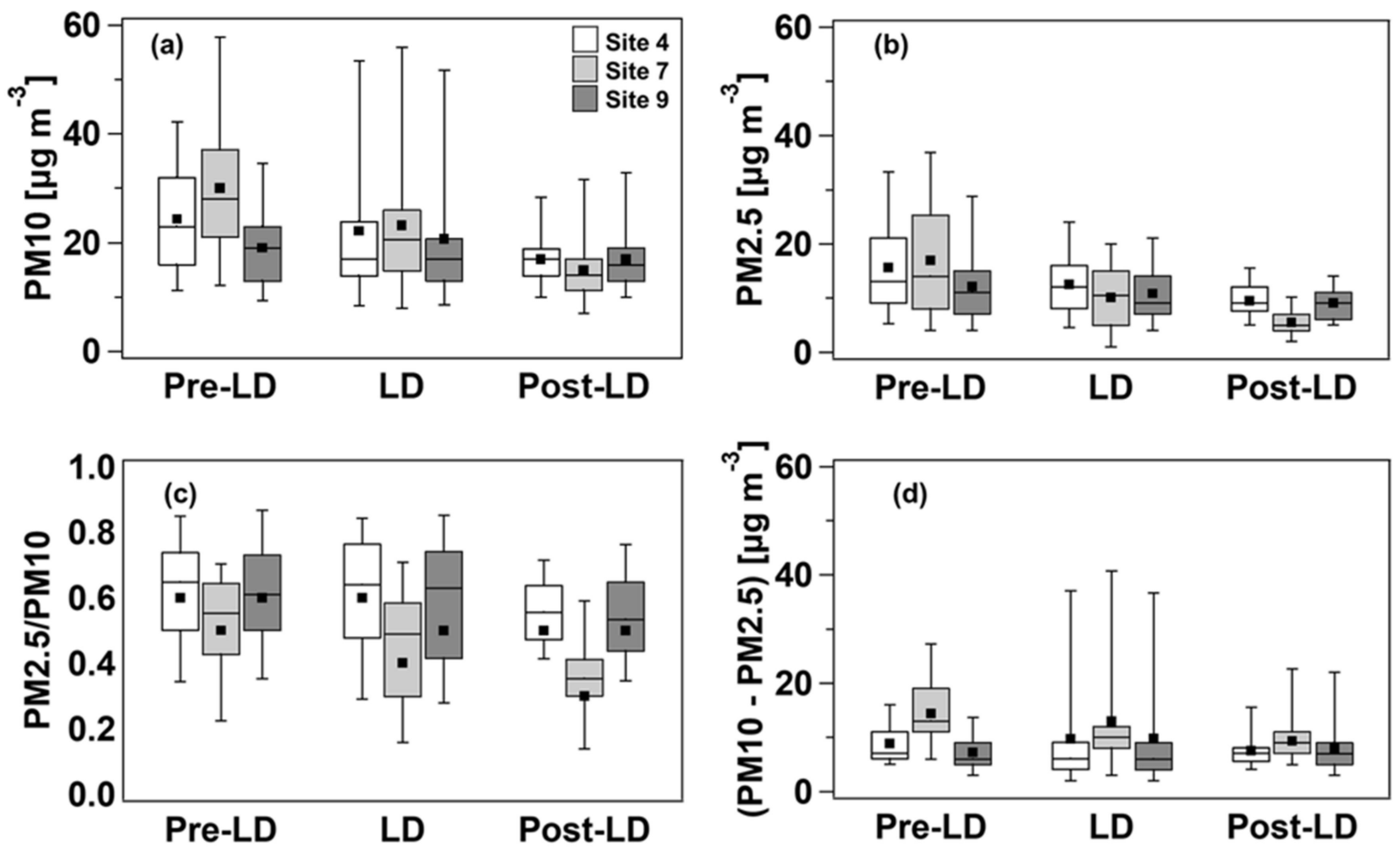

Figure 5. Box plots of (a) PM10 and (b) PM2.5 mass concentrations, (c) PM2.5/PM10 mass ratio, and (d) (PM10-PM2.5) mass concentrations of the Sites 4 (Lecce-Libertini, white box), 7 (Campi Salentina, light grey box), and 9 (Cerrate, dark grey box) in the Pre-LD (before lockdown), LD (during lockdown), and Post-LD (after lockdown) periods. Horizontal lines and dots in each box are the median and mean values, respectively. The 25th and the 75th percentiles are indicated by the lower and the upper boundaries of each box, respectively. The lower and upper whiskers represent the 5th and the 95th percentiles, respectively.

Comparison between PM Mass Concentrations in 2020 and Ref-Year

Ground-based PM2.5 and PM10 mass concentrations are also season-dependent at the study site, as columnar aerosol properties (Section 3.1.1). Therefore, PM2.5 and PM10 monthly concentrations of the year 2020 have been compared with the corresponding parameters of the ref-year to obtain a better estimate of the onset and duration of the LD measure impacts on the PM at the surface. Figure $\mathrm{S} 8$ shows by box plots the monthly evolution of PM2.5 and PM10 mass concentrations in 2020 and the ref-year at Sites 4, 7, and 9, highlighting that mean and median values of the PM10 mass concentrations on average increased in summer and that this effect was even larger for PM2.5 concentrations. However, the increasing rate was less evident in 2020 than in the ref-year, as the monthly column-based AOD box plots have also shown (Figure S3a). The stagnant atmospheric conditions prevailing in summer over the Mediterranean likely contributed to these results. The Mann-Whitney test was used to identify significant differences for PM2.5 and PM10 concentrations between each month of 2020 and the ref-year (Table S5). We found that in June, July, and August 2020 the PM2.5 and most of the PM10 mass concentrations were significantly smaller than the corresponding monthly means of the ref-year at the three sites, likely because of the LD measure impact. Therefore, last results can indicate that the LD measure effects on PM concentrations have likely been detected up to several months after the removal of the LD measures (17 May), as observed for columnar aerosol properties (Section 3.1.1).

Figure 6 shows the APD\% monthly evolution of PM10 (black) and PM2.5 (grey) mass concentrations at (a) Site 4, (c) 7, and (e) 9, to quantify the monthly mass concentration changes between 2020 and the ref-year and clearly identify the months significantly affected 
by LD measures. PM10 and PM2.5 concentrations of June, July, and August appear to have been mostly affected by the LD measures. The PM10 and PM2.5 June-APD $\%$ values were equal to $-33 \%$ and $-39 \%$, respectively, at Site 4 , to $-33 \%$ and $-57 \%$, respectively, at Site 7, and to $-35 \%$ and $-37 \%$, respectively, at Site 9 . These last results show that the APD\% was higher for PM2.5 than for PM10, besides confirming the LD impacts up to several months after the removal of the LD measures. Figure S9 shows the PM2.5 (grey line) and /or PM10 (black line) monthly APD\% at Site (a) 1, (b) 2, (c) 3, (d) 5, (e) 6, (f) 8, and (g) 10. All the seven sites reported in Figure S9 were characterized in June, July, and August by negative PM-APD\% values varying from site to site. The highest $\mathrm{PM} 10-\mathrm{APD} \%$ values $(-23 \%,-6 \%$, and $-10 \%$, in June, July, and August, respectively) were found at Site 10, which is a background site, while the smallest values (up to $-92 \%$ in June) were found at Site 6, which is a rural/industrial site. Wetchayont et al. [32] identified a reduction in PM2.5 concentration by $-15.79 \%$ in the LD period and by $-23.34 \%$ in the Post-LD period by analysing measurements performed in Bangkok (Thailand) in a highly urbanized area and considering the same reference years of this study. The PM2.5 and PM10 mass concentration reductions observed in 2020 with respect to the ref-year are within the variability range evaluated by Sicard et al. [31], who also considered 2017, 2018, and 2019 as reference years. They evaluated the PM concentration decrease in 4 southern European sites (Nice, Rome, Turin, and Valencia) and found an average reduction of $-8 \%$, which was significantly lower than the corresponding reduction estimated at Wuhan in China $(-42 \%)$.

Figure $6 \mathrm{~b}, \mathrm{~d}, \mathrm{f}$ show the APD $\%$ monthly evolution at Sites 4, 7, and 9, respectively, of (PM10-PM2.5) mass concentrations and PM2.5/PM10 mass ratios. Few studies have been devoted to the LD measure impacts on both parameters, while the LD effects on PM concentrations have been addressed by several works. The PM2.5/PM10 APD\% values assumed negative values at the three sites from May to October. This last result might suggest that the LD measure impact on the PM properties started to be significant since May and likely lasted up to October. The June, July, and August (PM10-PM2.5)-APD\% values are negative at Sites 4 and 9 and positive at Site 7, where PM2.5 mass concentrations significantly decreased as a consequence of the LD measures.

\subsection{Correlations between Columnar Aerosol Parameters and Corresponding PM2.5 and PM10 Mass Concentrations in the 2020- and Ref-Year}

Several studies have investigated the relationships between remotely-sensed AODs and PM mass concentrations at the surface, since AODs from surface- and satellite-based sensors could be used as a proxy for the surface PM2.5 and/or PM10 mass concentration estimates (e.g., [59]). One must be aware that remote sensing devices are sensitive to aerosol optical properties and, consequently, AODs depend on the aerosol extinction, absorption, and scattering in the atmospheric column. In contrast, PM mass concentrations depend on the particle gravimetric mass. Therefore, PM-AOD relationships are strongly dependent on both columnar and surface particle properties. AODs at $440 \mathrm{~nm}$ have been selected since they are also quite sensitive to fine particle contributions. The relationships between PM2.5 and PM10 mass concentrations and corresponding AODs (at $440 \mathrm{~nm}$ ) have been investigated in this section for the 2020- and the ref-year datasets in order to estimate how they were affected by the LD measures. Our analysis has been restricted to Site 4 because it represents the closest site (about $6 \mathrm{~km}$ away) to the AERONET photometer site (Site 11, Figure 1), where both PM2.5 and PM10 mass concentrations were available. We are aware that the two selected sites are characterized by a different monitoring area, as reported in Table S1. However, considering the closest sites among the analysed ones, we can minimize possible effects due to different sources/features that can differently affect the LD measure impacts. Figure 7 shows the PM2.5 and PM10 mass concentrations referring to Site 4 as a function of the corresponding AODs (at $440 \mathrm{~nm}$ ) for May, June, July, and August, since they were the months likely affected by the LD measures, in accordance with APD\% plots (Figure 6a,c,e). Firstly, in May (Figure 7a,b), we identified significant correlations (at the p-level $<0.05$, according to the two-tailed t-test) of both PM2.5 and PM10 concentration with corresponding AOD values in 2020, while the ref-year PM2.5- 
and PM10-AOD correlations were rather weak ( $\mathrm{r}=0.17$ and 0.11 , respectively). In June, the month most affected by the LD measures, we found a significant correlation between PM2.5 and AOD values at the $\mathrm{p}$-level $<0.05$, according to the two-tailed t-test, for both the 2020 $(\mathrm{r}=0.47)$ and the ref-year $(\mathrm{r}=0.46)$, as shown in Figure 7c. The main differences between the 2020- and the ref-year PM2.5-AOD relationships were mainly due to smaller PM2.5 concentrations and AOD values in 2020 than in the ref-year, because of the LD measure impact in 2020. Conversely, in June (Figure 7d) we identified a significant correlation (at the p-level < 0.02) between PM10 and AOD values in 2020 ( $\mathrm{r}=0.53)$, while the correlation was poor $(r=0.29)$ for the ref-year datasets. In July, the PM2.5- and PM10-AOD correlations were both statistically significant at the p-level $<0.05$ based on the two-tailed t-test both in 2020 and in ref-year (Figure 7e,f, respectively).
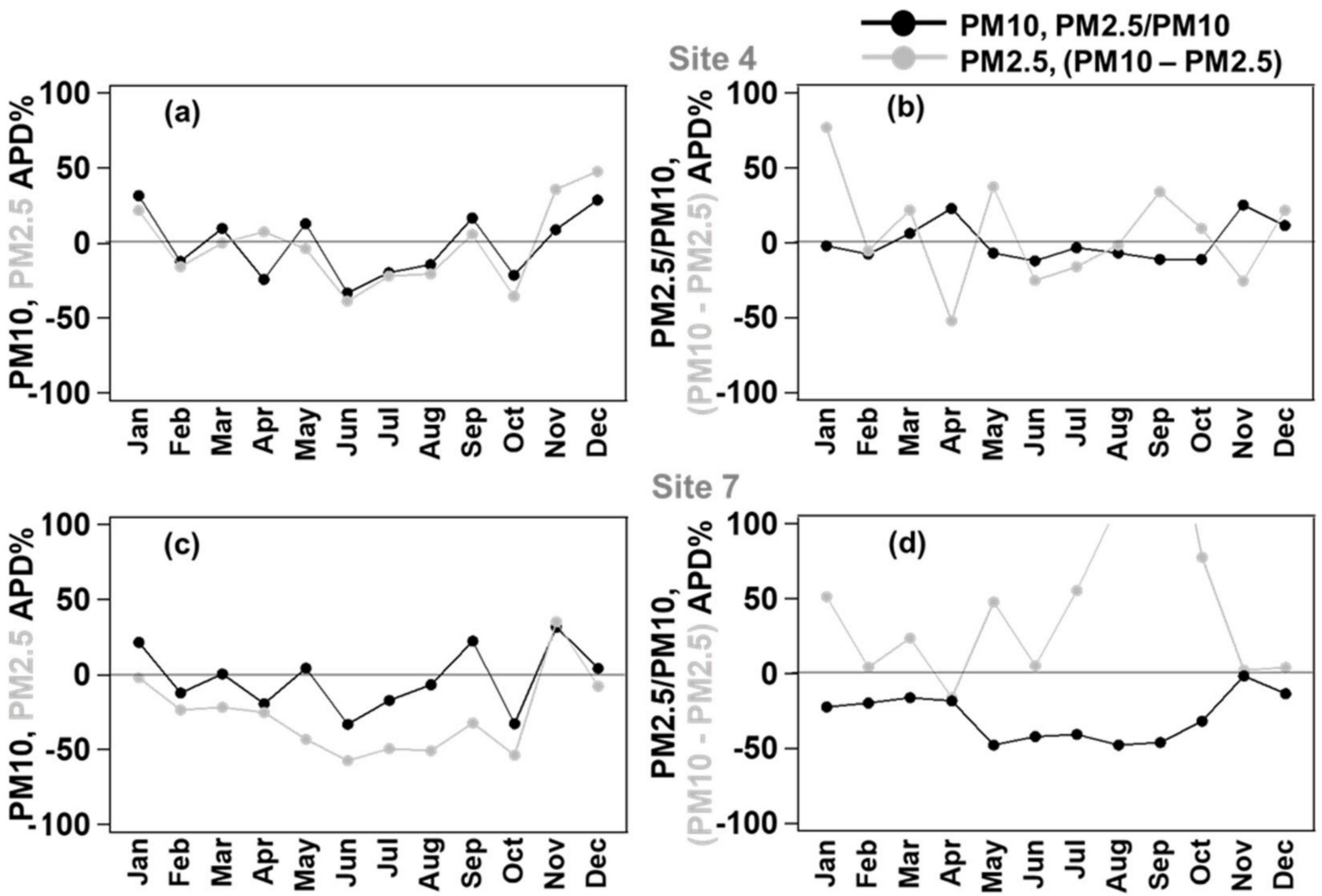

Site 7

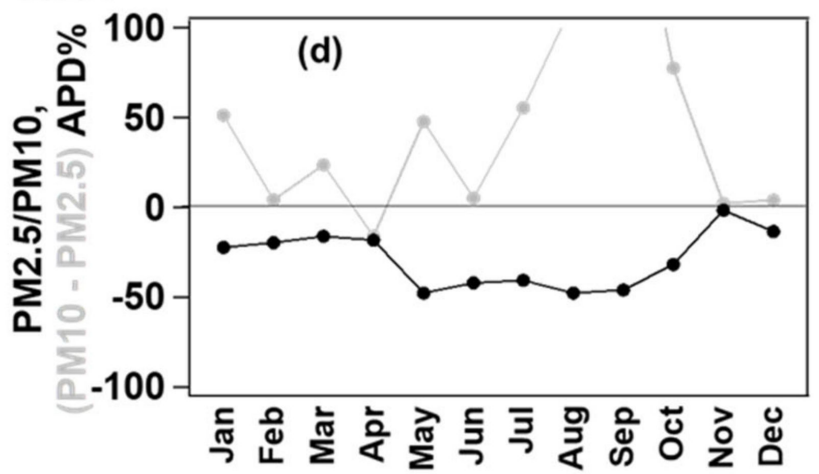

\section{Site 9}
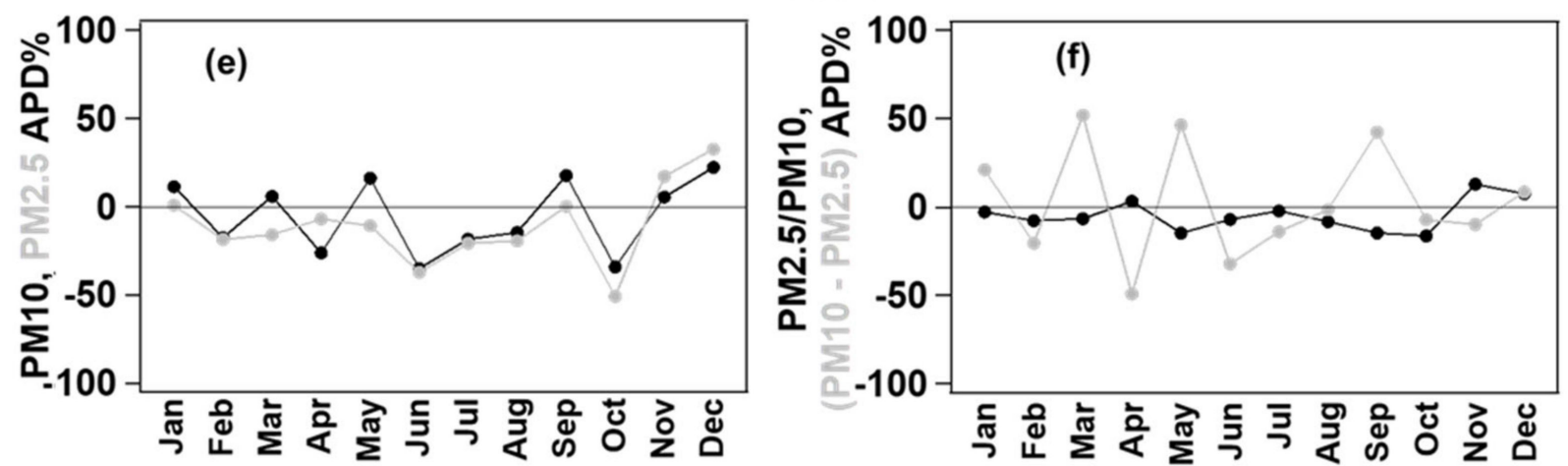

Figure 6. Monthly evolution of Average Percent Departure (APD\%) of PM10 (black) and PM2.5 (grey) mass concentration and of PM2.5/PM10 mass ratio (black) and (PM10-PM2.5) coarse fraction concentration (grey) for Site 4 (Lecce-Libertini; $(\mathbf{a}, \mathbf{b})$, respectively), for Site 7 (Campi Salentina; (c,d), respectively), and for Site 9 (Cerrate; (e,f), respectively). 

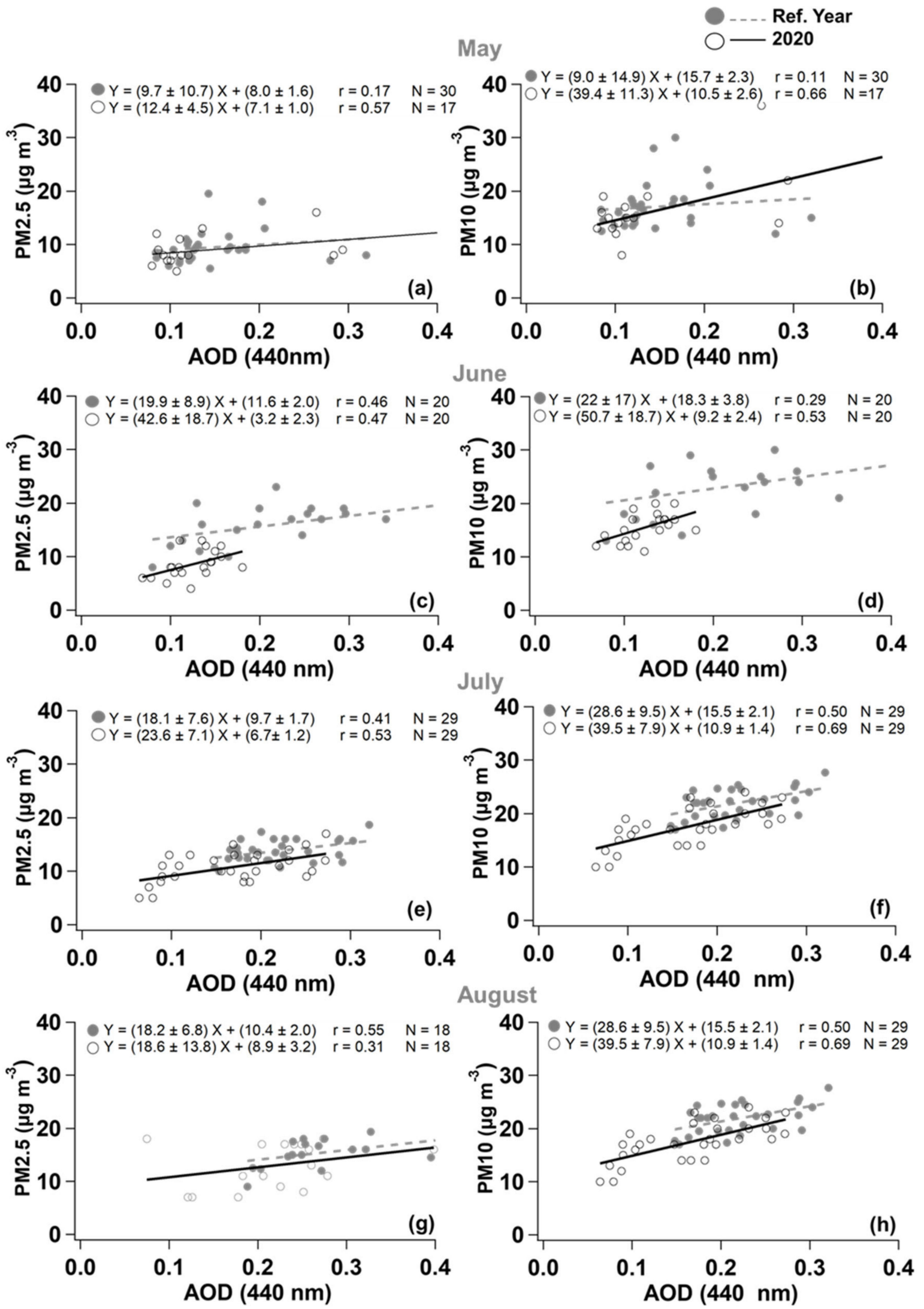

Figure 7. Scatterplot of PM2.5 and PM10 mass concentrations as a function of AOD (Aerosol Optical Depth) at $440 \mathrm{~nm}$, in May $(\mathbf{a}, \mathbf{b})$, in June (c,d), in July (e,f), and in August (g,h), respectively, for Site 4 (Lecce-Libertini). Full dots and circles represent data from the reference year (average of the years 2017, 2018, and 2019) and the year 2020, respectively. Fitting regression line equations, Pearson correlation coefficient $(\mathrm{r})$, and the number of points $(\mathrm{N})$ are also included. 
Finally, as shown in Figure 7g, the PM2.5-AOD correlation coefficient was low in 2020 $(r=0.31)$ in contrast to the corresponding ref-year r-value (0.55) in August. Conversely, in the same month we found a significant correlation between PM10 and AOD values at the $p$ level $<0.01$ both in $2020(r=0.69)$ and in ref-year $(r=0.50)$ (Figure $7 \mathrm{~h})$. Therefore, PM2.5 and PM10 mass concentrations were on average correlated with the corresponding AODs at Site 4 in both the 2020 and the ref-year. The smaller variability range of PM mass concentrations and AOD values in 2020 than in the ref-year represented the main difference, which was quite marked in June, the month most affected by the LD measures, and decreased from July to August. The weak dependence of the correlation's slopes between the 2020 and the ref-year ones could likely indicate that both PM mass concentrations and AOD values were similarly affected by the LD measures.

We have also investigated the relationships between the PM2.5/PM10 mass ratio and the Ångström exponent, which are related to the size distribution of the surface and columnar aerosol properties, respectively. Figure 8 shows the PM2.5/PM10 ratio as a function of $\AA$ in May, June, July, and August referring to Site 4 for both the 2020- and the ref-year. Observe from Figure 8 that almost all the reported correlations were statistically significant at the p-level $<0.05$ based on the two-tailed t-test and that the correlation's slopes appear to have not been significantly affected by the 2020-LD measures. The LD measures appear to have only affected the variability range of the PM2.5/PM10 ratio and the $\AA$ values mainly in June since it was the month mostly affected by the LD measures, as Figure $8 \mathrm{~b}$ clearly shows. The rather poor correlation between the two parameters estimated in May $2020(r=0.10$, Figure 8a) likely occurred because ground- and column-based aerosol properties were differently affected by the LD measures. Conversely, note that PM2.5/PM10 and $\AA$ were significantly correlated $(r=0.63)$ in May of the ref-year. In conclusion, the small differences between the 2020 and the corresponding ref-year investigated aerosol parameters (Figures 7 and 8) likely occurred because both PM concentrations and columnar aerosol parameters were similarly affected by the LD measures. The similar PM and AOD APD\% trends (resulting from comparison of Figure 6a with Figure 3a) support the previous comment.

\section{4. $\mathrm{NO}_{2}, \mathrm{CO}$, and $\mathrm{SO}_{2}$ Mass Concentrations before, during, and after the Lockdown}

To have a comprehensive picture of the LD restriction impacts on air pollution at the monitoring area of this study, we also investigated the LD effects on the mass concentrations of some gaseous pollutants. According to Table $\mathrm{S} 1$, nitrogen dioxide $\left(\mathrm{NO}_{2}\right)$ and carbon monoxide (CO) were the gaseous pollutants monitored at Site 4 , while $\mathrm{NO}_{2}$ was the only gas monitored at Sites 7 and 9. The time series of their mass concentrations during the PreLD, LD, and Post-LD periods are reported in Figure S10. Discontinuities in the time series are due to technical reasons. The $\mathrm{NO}_{2}$ corresponding box plots are shown in Figure 9a for the three analysed sites. In contrast to PM10 and PM2.5 mass concentrations, the LD impact on $\mathrm{NO}_{2}$ mass concentrations was observed immediately after the onset of the LD restrictions, as Figure S10 and Figure 9a clearly show. Table S4 shows that the differences between the Pre-LD and the $\mathrm{LD} \mathrm{NO}_{2}$ mass concentrations were statistically significant at the $\mathrm{p}$-level $<0.001$ at the three sites. These results are strictly related to the reduction in the road traffic, because of the LD restrictions, since traffic generally represents the main outdoor source of $\mathrm{NO}_{2}$ (e.g., [54,56]). Consequently, Figure 9a shows that the highest Pre-LD NO 2 mass concentrations were monitored at Site 4 that is an urban site. 


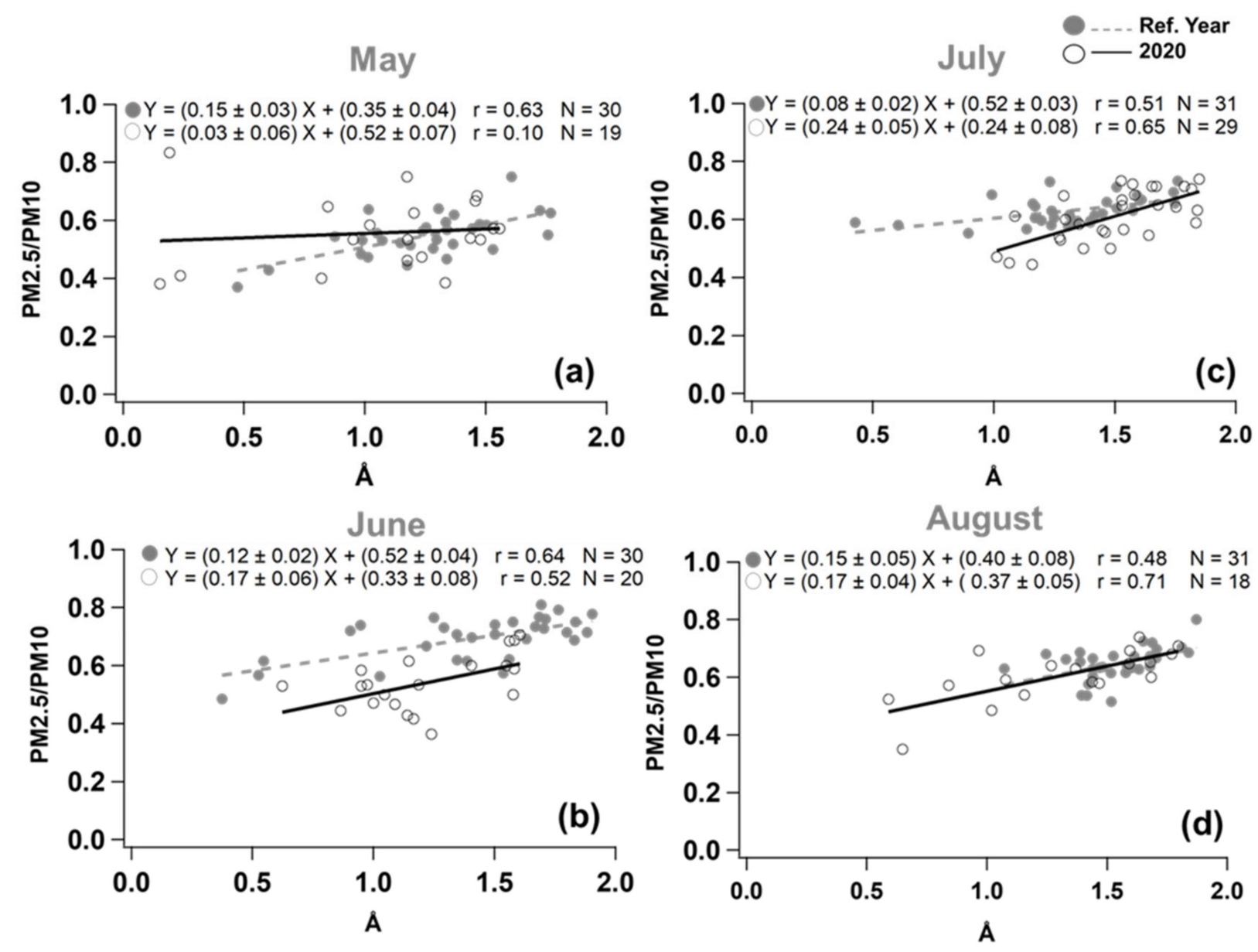

Figure 8. Scatterplot of PM2.5/PM10 mass ratio as a function of $\AA$ ( $\mathrm{n}$ gström exponent at the wavelength pair $440-870 \mathrm{~nm}$ ) in (a) May, (b) June, (c) July, and (d) August for Site 4 (Lecce-Libertini). Full dots and circles represent data from the reference year (average of the years 2017, 2018, and 2019) and the year 2020, respectively. Fitting regression line equations, Pearson correlation coefficient (r), and the number of points (N) are also included.

Another relevant effect clearly shown by Figure $\mathrm{S} 10$ and Figure 9 a is the weak $\mathrm{NO}_{2}$ concentration increase during the Post-LD after the first release of the LD measures, confirming the strong correlation between anthropogenic activities and $\mathrm{NO}_{2}$ concentrations. The $\mathrm{NO}_{2}$ mass concentration increase in the Post-LD period was higher at Site 4 than at Sites 7 and 9 since road traffic emissions rapidly increased after the removal of LD restrictions at the urban site (Figure S10 and Figure 9a). Accordingly, Table S4 shows a statistically significant difference between the LD and the Post-LD period (at the p-level $<0.001$ ) based on the Dunn's pairwise test only at urban Site 4 . The CO mass concentration also suddenly decreased immediately after the beginning of the LD restrictions at Site 4 (Figure S10a). In fact, cars, trucks, and all the other vehicles or machinery that burn fossil fuels (with incomplete combustion processes) are the greatest $\mathrm{CO}$ sources [60], whose emissions were all affected by the LD restrictions. The Pre-LD, LD, and Post-LD CO box plots are then shown in Figure 9b. The results on the significance of the differences between different periods are shown in Table S4. Figure 9c illustrates the Pre-LD, LD, and Post-LD box plots of the $\mathrm{NO}_{2} / \mathrm{CO}$ ratio, because this parameter was generally used to determine the relative contributions from combustion sources and road traffic (e.g., [61,62]). We found a significant increase in the mean values of the $\mathrm{NO}_{2} / \mathrm{CO}$ ratio in Post-LD period with respect to the corresponding values in Pre-LD and LD periods. The reason of this effect could be associated with the considerable decrease in the heavy-goods vehicle traffic due to the lockdown measures, because these vehicles are generally the most responsible for the $\mathrm{CO}$ emission. Finally, we also investigated the $\mathrm{LD}$ restriction effects on the $\mathrm{SO}_{2}$ mass concentra- 
tions that were only monitored at Site 1 (Maglie, urban) and Site 6 (Surbo, rural/industrial) among the studied sites (Table S1). The corresponding box plots are reported in Figure $9 \mathrm{~d}$, which shows a significant decrease in the $\mathrm{SO}_{2}$ concentrations mainly from the Pre-LD to the $\mathrm{LD}$ periods at both sites. Note that the largest sources of $\mathrm{SO}_{2}$ are generally associated with the burning of fossil fuels by power plants and other industrial facilities and/or processes (e.g., [60]).
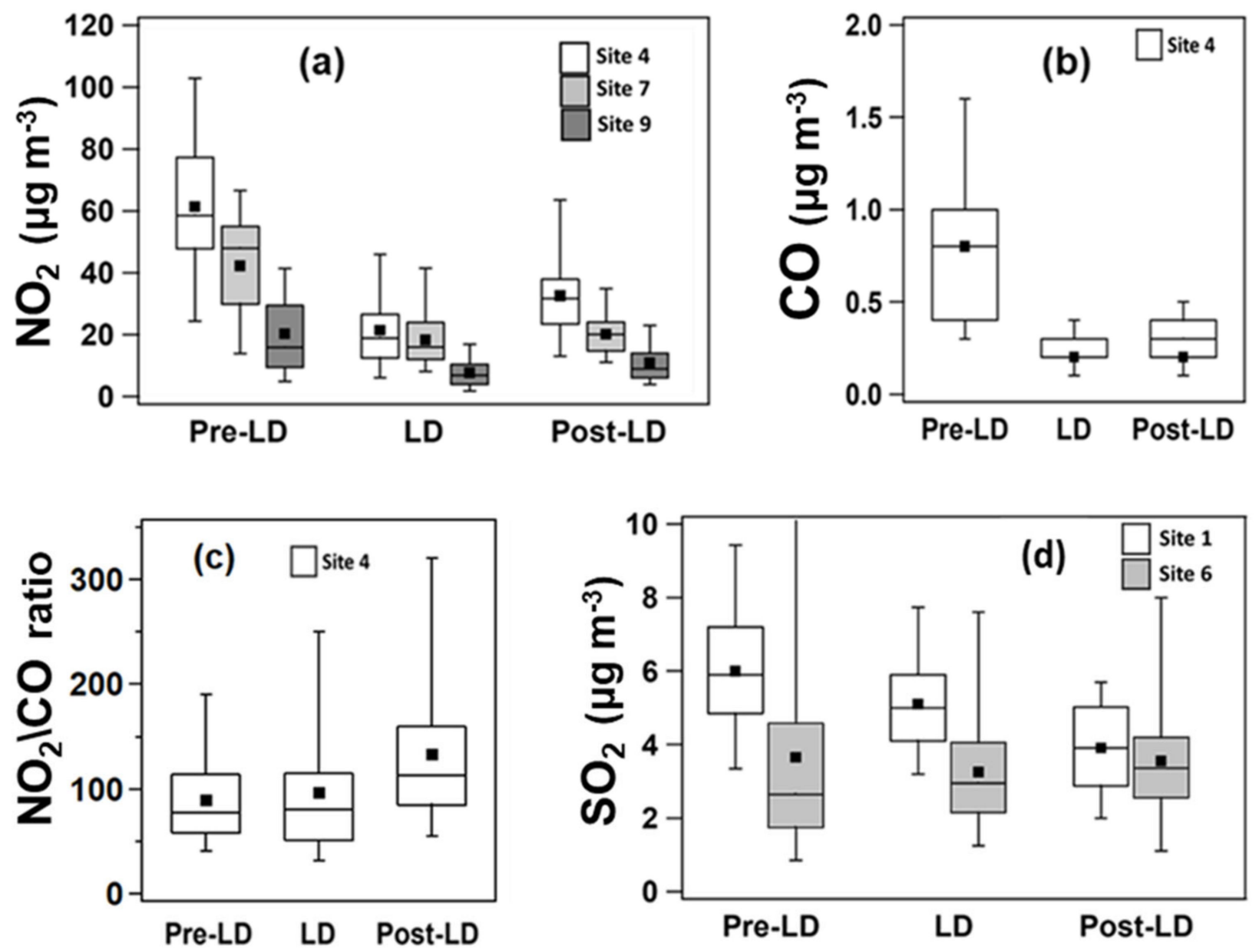

Figure 9. (a) Box plots of $\mathrm{NO}_{2}$ mass concentration for Sites 4 (Lecce-Libertini, white boxes), 7 (Campi Salentina, light grey boxes), and 9 (Cerrate, dark grey boxes) in the Pre-LD (before lockdown), LD (during lockdown), and Post-LD (after lockdown) periods. Box plots of (b) $\mathrm{CO}$ mass concentration and (c) $\mathrm{NO}_{2} / \mathrm{CO}$ ratio for Site 4 in the Pre-LD, LD, and Post-LD periods. (d) Box plots of $\mathrm{SO}_{2}$ mass concentration for Site 1 (Maglie, white boxes) and Site 6 (Surbo, grey boxes) in the Pre-LD, LD, and Post-LD periods. Horizontal lines and dots in each box are the median and mean values, respectively. The 25 th and the 75th percentiles are indicated by the lower and the upper boundaries of each box, respectively. The lower and upper whiskers represent the 5 th and the 95 th percentiles, respectively.

The results reported in this study regarding the gaseous pollutant and PM concentration time evolution after the beginning of the LD measures are basically in agreement with those reported in other previous works. In fact, Teixidó et al. [63] analysed $\mathrm{NO}_{2}, \mathrm{SO}_{2}$, and CO concentration in Abu Dhabi (UAE) in the Pre-LD (1 January-21 March), LD (22 March-24 June), and Post-LD period (25 June-24 October) and found a decrease in $\mathrm{NO}_{2}$ concentrations by $-40.0 \%$ in the LD and $-35.8 \%$ in the Post-LD with respect to the Pre-LD period. Lower concentration reductions were found for $\mathrm{SO}_{2}$ and $\mathrm{CO}$ concentration (in the range from $-12.2 \%$ to $-31.0 \%$ ). Conversely, they observed a PM concentration increase during the LD and Post-LD periods with respect to the Pre-LD period (in the range from $+33.4 \%$ to $+71.1 \%$ ) as a result of the influence from natural events (sand and dust storms) 
and other anthropogenic sources. In Naples (Italy), Sannino et al. [47] found a significant reduction in $\mathrm{NO}_{2}$ concentration (from -49 to $-62 \%$ ) in urban/suburban area, while $\mathrm{CO}$ and $\mathrm{SO}_{2}$ presented a larger reduction in urban or industrial sites (up to $-58 \%$ and $-70 \%$, respectively). PM concentrations were instead characterized by lower reductions (up to $-49 \%$ ). In an urban context and in a traffic site in Barcelona (Spain), Tobias et al. [56] found a similar decrease in PM10 ( -27.8 and $-31.0 \%$, respectively) and $\mathrm{NO}_{2}(-47.0$ and $-51.4 \%$, respectively) in the LD period compared to the Pre-LD period. Moreover, in this case, the authors explained that the lower PM10 reductions compared to the $\mathrm{NO}_{2}$ ones were related to some desert dust outbreaks during the LD period.

Comparison of the Monthly $\mathrm{NO}_{2}, \mathrm{CO}$, and $\mathrm{SO}_{2}$ Mass Concentrations of the Year 2020 with the Corresponding Ref-Year Ones

The $\mathrm{NO}_{2}, \mathrm{CO}$, and $\mathrm{SO}_{2}$ mass concentrations of the year 2020 have been compared with the corresponding concentrations of the ref-year to obtain a better estimate of the onset and duration of the LD measure impacts on their concentrations. Figure S11a,b show the monthly box plots of $\mathrm{NO}_{2}$ and $\mathrm{CO}$ concentration for Site 4 (urban), while Figure 10 shows the mass-concentration APD\% monthly evolution of (a) $\mathrm{NO}_{2}$ and $\mathrm{CO}$ at Site 4 (urban) and $\mathrm{NO}_{2}$ at (b) Site 7 (suburban) and (c) Site 9 (background). The $\mathrm{SO}_{2} \mathrm{APD} \%$ monthly evolution is then reported in Figure $10 \mathrm{~d}$ for the urban Site 1 and the rural/industrial Site 6. Figure S11a and Figure 10a,c show that the LD measure impact on $\mathrm{NO}_{2}$ mass concentrations was clearly observed since March at Sites 4 and 9, respectively, reached the smallest value in April (APD $\%=-64 \%$ at Site 4 and $-38 \%$ at Site 9 ), and likely lasted up July and September at Site 4 and 9 , respectively. In contrast, the $\mathrm{NO}_{2}$ concentration was mainly affected by the LD measures only in April (-31\%) at Site 7. Figure 10a shows that the CO APD \% at Site 4 decreased up $-41 \%$ in March, reached the minimum value in May $(-62 \%)$, and the negative APD \% values lasted up to November $(-36 \%)$. The monthly differences between the $2020 \mathrm{CO}$ concentrations and the corresponding ref-year ones (Figure S11b) were statistically significant at p-level $<0.001$ from March up to October (Table S5). Figure S11c illustrates the monthly box plots of the $\mathrm{NO}_{2} / \mathrm{CO}$ ratio, generally used to determine the relative contributions from combustion sources and road traffic, as reported in the previous section. We found a significant increase in the monthly mean values of the $\mathrm{NO}_{2} / \mathrm{CO}$ ratio in 2020 with respect to the corresponding values in ref-year from May to October, probably associated with the considerable decrease in the heavygoods vehicle traffic due to the lockdown measures. The APD\% monthly evolution in Figure $10 \mathrm{~d}$ indicates that the LD measure impact on the $\mathrm{SO}_{2}$ mass concentrations likely started to be observed since May and lasted up to August at both Sites 1 and 6. The smallest $\mathrm{APD} \%$ value was reached in June (-59\%) at the urban Site 1 and in August $(-56 \%)$ at the rural/industrial Site 6 . In conclusion, besides showing that the APD\% monthly time series were site-dependent for each tested gaseous pollutants, the results reported in this section have indicated that the LD measures likely affected the $\mathrm{NO}_{2}$ and $\mathrm{CO}$ mass concentrations since March, and the minimum APD\% value was observed in April. In contrast, the highest LD measure impact on $\mathrm{SO}_{2}$ mass concentrations was observed in June at Site 1 and in August at Site 6.

The results on the LD measure impact on gaseous pollutants reported in this study are in accordance with most of the previous works comparing the changes during the 2020 lockdowns against relative control periods of previous years (e.g., [10,54,64,65]). In particular, they have reported $\mathrm{NO}_{2}$ concentrations on average reduced by 30-60\%. Grivas et al. [55] observed in Athens (Greece) that the concentration of a traffic-related pollutant as $\mathrm{NO}_{2}$ significantly decreased (-42\%) during the LD period compared to the same period in the years 2016-2019. Conversely, a lower decrease of $-10 \%$ and an increase of $+9 \%$ were observed for the Pre- and Post-LD periods, respectively, between the year 2020 and the relative periods of the years 2016-2019. 

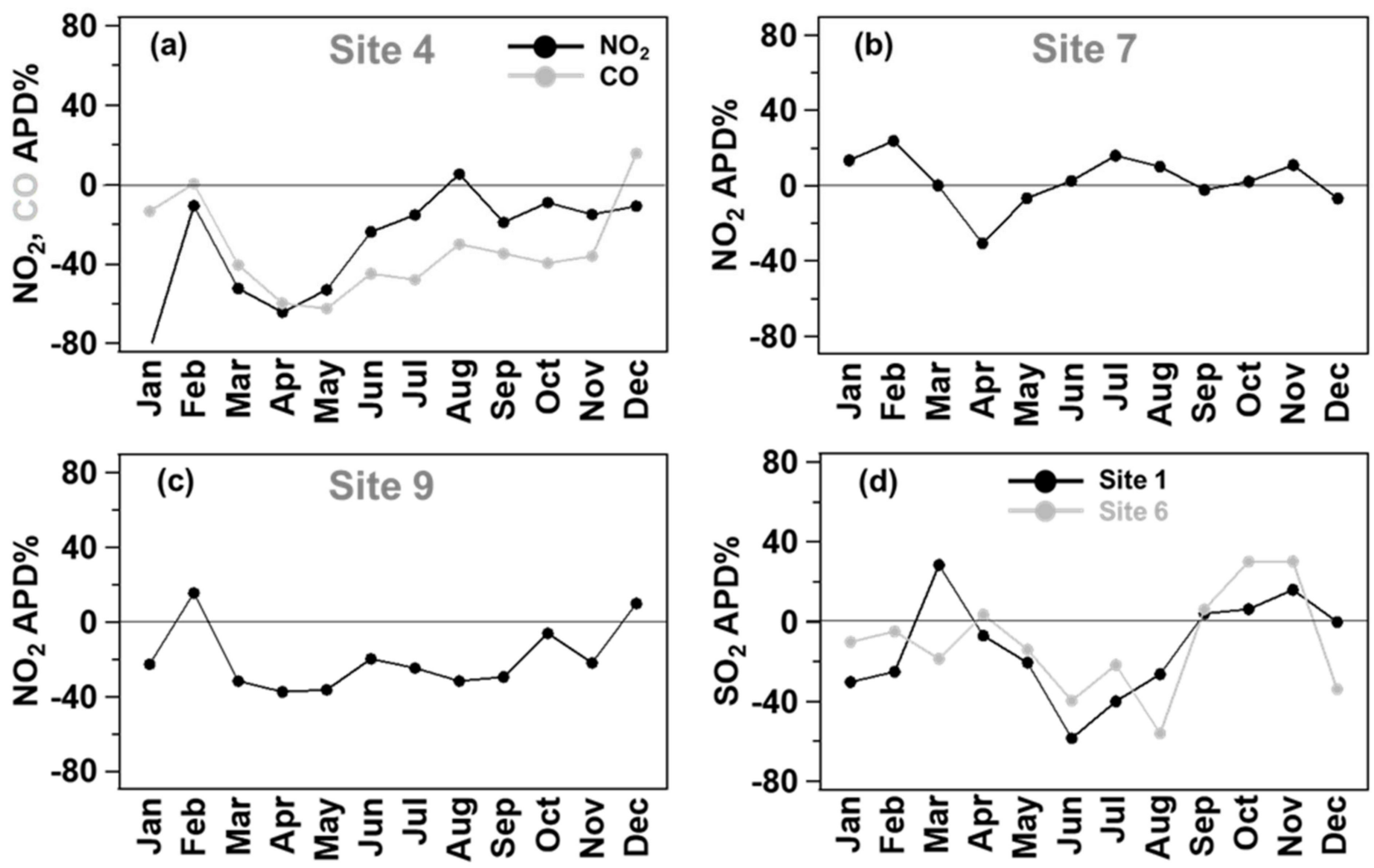

Figure 10. Monthly evolution of Average Percent Departure (APD\%) of (a) $\mathrm{NO}_{2}$ (black) and CO (grey) mass concentration for Site 4 (Lecce-Libertini), $\mathrm{NO}_{2}$ mass concentration for (b) Site 7 (Campi Salentina) and (c) Site 9 (Cerrate), and (d) SO 2 mass concentration for Site 1 (Maglie, black) and Site 6 (Surbo, grey).

\section{Summary and Conclusions}

Measurements performed before, during, and after the Italian COVID-19 LD restrictions have been analysed to investigate the LD measure impacts on both column- and ground-based air pollution parameters over south-eastern Italy. The whole 2020-year measurements of the selected air pollution parameters have been compared with the corresponding ones of a ref-year, based on the 2017, 2018, and 2019 measurements, to better identify/quantify the duration of the LD measure impact on pollutants. The comparison of the COVID19-LD effects on ground-level air pollutant properties, mostly affected by local meteorology and pollution sources, with those on the columnar aerosol particles, which are instead mostly affected by long-range transboundary air pollution, represents one of the main novel contributions of this study. The main results of this study are summarized below.

- Sun/sky photometer measurements have highlighted a significant decrease in the columnar aerosol load (by AOD) and a change of the mean particle size/type (by $\AA$ and $\Delta \AA$ ) in 2020. The highest changes were observed in the few months after the LD measure start time;

- The analysis of the $\mathrm{AOD}, \AA$, and $\Delta \AA$ variability range by colour-coded scatter-plots referring to the 2020 and the ref-year has allowed inferring that the columnar aerosol load was in June, July, and August 2020 less affected by continental urban/industrial particles than in the ref-year;

- The APD\% monthly evolution of PM mass concentrations was characterized by a trend similar to the one of AOD-APD\%, highlighting a similar effect of the LD restrictions on column- and ground-based extensive particle parameter;

- The LD restrictions were responsible for larger PM2.5 concentration reductions compared to the corresponding PM10 ones; 
- $\quad$ PM-APD\% values were highly site-dependent with larger decreases on average detected at urban and suburban sites than at background sites. In fact, the minimum monthly PM2.5-APD $\%$ detected in June was $-57 \%$ at a suburban site and $-37 \%$ at a background site;

- Both column- (AODs) and ground-based (PMs) particle parameters were similarly affected by the LD restrictions;

- The impact of the LD measures on gaseous pollutant $\left(\mathrm{NO}_{2}, \mathrm{CO}\right.$, and $\left.\mathrm{SO}_{2}\right)$ mass concentrations was on average observed immediately after the LD measure onset, in contrast to aerosol parameters. In fact, gaseous pollutants are directly emitted in the atmosphere from their sources, while most atmospheric particles are formed from gas-to-particle conversion, coagulation, and/or mixing processes.

In conclusion, the paper results have likely contributed to the characterization of the LD measure impacts over the Central Mediterranean basin, which is an area quite sensitive to the current climate changes, and have also shown that the LD measure impacts on pollution lasted several months after the LD measure removal. Paper results could likely contribute to the development of new procedures for the management and control of the air quality.

Supplementary Materials: The following are available online at https:/ /www.mdpi.com/article/ 10.3390/atmos12101366/s1, Figure S1: time series of aerosol optical depth, Ångström exponent, and its difference, Figure S2: overview of the comparison between the AOD in 2020 and in refyear, Figure S3: monthly box plots of aerosol optical depth, Ångström exponent, and its difference, Figure S4: monthly APD\% for AOD in 2020 with respect to 2017, 2018, and 2019, Figure S5: time series of PM10, PM2.5, and coarse fraction concentrations and PM2.5/PM10 ratio, Figure S6: time series of PM10 and PM2.5 mass concentrations for the other analysed sites, Figure S7: box plots of PM10, PM2.5, and (PM10-PM2.5) mass concentrations and PM2.5/PM10 mass ratios for the other analysed sites, Figure S8: monthly box plots of PM10 and PM2.5 mass concentrations for Sites 4, 7, and 9, Figure S9: monthly evolution of APD $\%$ of PM10 and PM2.5 mass concentrations for the other analysed sites, Figure S10: time series of $\mathrm{NO} 2$ and CO concentration for Sites 4, 7, and 9, Figure S11: monthly box plots of $\mathrm{NO} 2$ and CO concentration and NO2/CO ratio, Table S1: details of the analysed monitoring sites, Table S2: statistical tests among Pre-LD, LD, and Post-LD columnar aerosol parameters, Table S3: statistical test between 2020 and ref-year monthly values for columnar aerosol parameters, Table S4: statistical tests among Pre-LD, LD, and Post-LD PM and gaseous pollutant parameters, Table S5: statistical test between 2020 and ref-year monthly values for PM and gaseous pollutant parameters.

Author Contributions: Conceptualization: S.R.; Methodology: S.R.; Software: V.C. and F.P.; Validation: S.R.; Formal analysis: S.R.; Investigation: all authors; Resources: all authors; Data curation: all authors; Writing—Original Draft: S.R.; Writing—review \& editing: S.R.; Visualization: all authors; Supervision: S.R. All authors have read and agreed to the published version of the manuscript.

Funding: S. Romano has carried out this work with the support of a Temporary Researcher position financed by the Italian "Programma Operativo Nazionale (PON) Ricerca e Innovazione 2014-2020 (Azione I.2-Attrazione e Mobilità dei Ricercatori)—project AIM1800370-1. V. Catanzaro has carried out this work with the support of a fellowship financed by the Italian "PON Ricerca e Innovazione 2014-2020" in the frame of the Project CIR01_00015_464576. The work was partially supported by INFN (Istituto Nazionale Fisica Nucleare) of Italy, in the frame of the projects IS_ABS (Integrated System for Aerosol and Bioaerosol Studies at the Pierre Auger Observatory) and AT_SVB (Airborne Transmission of SARS-CoV-2, Viruses and Bacteria in workplaces), and by the Project PER-ACTRIS-IT Enhancement of the Italian component of the Aerosol Research Infrastructure, Clouds and Trace Gases Research Infrastructure (PIR01_00015).

Institutional Review Board Statement: Not applicable.

Informed Consent Statement: Not applicable.

Data Availability Statement: Data is contained within the article or Supplementary Material. 
Acknowledgments: The NOAA Air Resources Laboratory is kindly acknowledged for the provision of the HYSPLIT back-trajectories, as well as the Barcelona Supercomputing Centre for the provision of the dust load maps. M.R. Perrone is acknowledged for the fruitful discussions and her contribution to the manuscript supervision.

Conflicts of Interest: The authors declare no conflict of interest.

\section{References}

1. Gorbalenya, A.E.; Baker, S.C.; Baric, R.S.; de Groot, R.J.; Drosten, C.; Gulyaeva, A.A.; Haagmans, B.L.; Lauber, C.; Leontovich, A.M.; Neuman, B.W.; et al. Severe acute respiratory syndrome-related coronavirus: The species and its viruses-a statement of the coronavirus study group. Nat. Microbiol. 2020, 5, 536-544. [CrossRef]

2. Lai, A.; Chang, M.L.; O’Donnell, R.P.; Zhou, C.; Sumner, J.A.; Hsiai, T.K. Association of COVID-19 transmission with high levels of ambient pollutants: Initiation and impact of the inflammatory response on cardiopulmonary disease. Sci. Total Environ. 2021, 779, 146464. [CrossRef]

3. Cao, Y.; Shao, L.; Jones, T.; Oliveira, M.L.S.; Ge, S.; Feng, X.; Silva, L.F.O.; BéruBée, K. Multiple relationships between aerosol and COVID-19: A framework for global studies. Gondwana Res. 2021, 93, 243-251. [CrossRef]

4. Eleftheriadis, K.; Gini, M.I.; Diapouli, E.; Vratolis, S.; Vasilatou, V.; Fetfatzis, P.; Manousakas, M.I. Aerosol microphysics and chemistry reveal the COVID19 lockdown impact on urban air quality. Sci. Rep. 2021, 11, 1-11. [CrossRef]

5. Gama, C.; Relvas, H.; Lopes, M.; Monteiro, A. The impact of COVID-19 on air quality levels in Portugal: A way to assess traffic contribution. Environ. Res. 2021, 193, 110515. [CrossRef]

6. Jarvis, M.C. Aerosol Transmission of SARS-CoV-2: Physical Principles and Implications. Public Health Front. 2020, 8, 813. [CrossRef] [PubMed]

7. Venter, Z.S.; Aunan, K.; Chowdhury, S.; Lelieveld, J. COVID-19 lockdowns cause global air pollution declines. PNAS 2020, 117, 18984-18990. [CrossRef] [PubMed]

8. Gkatzelis, G.I.; Gilman, J.B.; Brown, S.S.; Eskes, H.; Gomes, A.R.; Lange, A.C.; McDonald, B.C.; Peischl, J.; Petzold, A.; Thompson, C.R.; et al. The global impacts of COVID-19 lockdowns on urban air pollution: A critical review and recommendations. Elem. Sci. Anth. 2021, 9, 00176. [CrossRef]

9. Lonati, G.; Riva, F. Regional scale impact of the COVID-19 Lockdown on Air Quality: Gaseous Pollutants in the Po Valley, Northern Italy. Atmosphere 2021, 12, 264. [CrossRef]

10. Kerimray, A.; Baimatova, N.; Ibragimova, O.P.; Bukenov, B.; Kenessov, B.; Plotitsyn, P.; Karaca, F. Assessing air quality changes in large cities during COVID-19 lockdowns: The impacts of traffic-free urban conditions in Almaty, Kazakhstan. Sci. Total Environ. 2020, 15, 730-139179. [CrossRef]

11. Li, J.Y.; Tartarini, F. Changes in air quality during the COVID-19 lockdown in Singapore and associations with human mobility trends. Aerosol Air Qual. Res. 2020, 20, 1748-1758. [CrossRef]

12. Arregocés, A.; Roberto, R.; Restrepo, G. Effects of Lockdown due to the COVID-19 Pandemic on Air Quality at Latin America's Largest Open-pit Coal Mine. Aerosol Air Qual. Res. 2021, 21, 200664. [CrossRef]

13. Donzelli, G.; Cioni, L.; Cancellieri, M.; Llopis-Morales, A.; Morales-Suárez-Varela, M. Relations between Air Quality and COVID-19 Lockdown in Valencia, Spain. Int. J. Environ. Res. Public Health 2021, 18, 2296. [CrossRef] [PubMed]

14. Brancher, M. Increased ozone pollution alongside reduced nitrogen dioxideconcentrations during Vienna'sfirst COVID-19 lockdown: Significance for air quality management. Environ. Pollut. 2021, 284, 117153. [CrossRef] [PubMed]

15. Goldberg, D.L.; Anenberg, S.C.; Griffin, D.; McLinden, C.A.; Lu, Z.; Streets, D.G. Disentangling the Impact of the COVID-19 Lockdownson Urban $\mathrm{NO}_{2}$ From Natural Variability. Geophys. Res. Lett. 2020, 47, 17. [CrossRef] [PubMed]

16. Lamprecht, C.; Graus, M.; Striednig, M.; Stichaner, M.; Karl, T. Decoupling of urban $\mathrm{CO}_{2}$ and air pollutant emission reductions during the European SARS-CoV-2 lockdown. Atmos. Chem. Phys. 2021, 21, 3091-3102. [CrossRef]

17. Sulaymon, I.D.; Zhang, Y.; Hopke, P.K.; Zhang, Y.; Hua, J.; Mei, X. COVID-19 pandemic in Wuhan: Ambient air quality and the relationships between criteria air pollutants and meteorological variables before, during, and after lockdown. Atmos. Res. 2021, 250, 105362. [CrossRef]

18. Albayati, N.; Waisi, B.; Al-Furaiji, M.; Kadhom, M.; Alalwan, H. Effect of COVID-19 on air quality and pollution in different countries. J. Transp. Health 2021, 21, 101061. [CrossRef]

19. Skirienè, A.F.; Stasiškienè, Ž. COVID-19 and Air Pollution: Measuring Pandemic Impact to Air Quality in Five European Countries. Atmosphere 2021, 12, 290. [CrossRef]

20. Munir, S.; Luo, Z.; Dixon, T. Comparing different approaches for assessing the impact of COVID-19 lockdown on urban air quality in Reading, UK. Atmos. Res. 2021, 261, 105730. [CrossRef]

21. Marinello, S.; Lolli, F.; Gamberini, R. The Impact of the COVID-19 Emergency on Local Vehicular Traffic and Its Consequences for the Environment: The Case of the City of Reggio Emilia (Italy). Sustainability 2021, 13, 118. [CrossRef]

22. Campanelli, M.; Iannarelli, A.M.; Mevi, G.; Casadio, S.; Diémoz, H.; Finardi, S.; Dinoi, A.; Castelli, E.; Di Sarra, A.; Di Bernardino, A.; et al. A wide-ranging investigation of the COVID-19 lockdown effects on the atmospheric composition in various Italian urban sites (AER-LOCUS). Urban Clim. 2021, 39, 100954. [CrossRef]

23. Shen, L.; Zhao, T.; Wang, H.; Liu, J.; Bai, Y.; Kong, S.; Zheng, H.; Zhu, Y.; Shu, Z. Importance of meteorology in air pollution events during the city lockdown for COVID-19 in Hubei Province, Central China. Sci. Total Environ. 2021, 754, 142227. [CrossRef] 
24. Sarla, S.; Srivastava, A.K.; Ahlawat, A.; Mishra, S.K. Impact of COVID-19 lockdown on aerosol optical and radiative properties over Indo-Gangetic Plain. Urban Clim. 2021, 37, 100839. [CrossRef]

25. Acharya, P.; Barik, G.; Gayen, B.K.; Bar, S.; Maiti, A.; Sarkar, A.; Ghosh, S.; De, S.K.; Sreekesh, S. Revisiting the levels of Aerosol Optical Depth in south-southeast Asia, Europe and USA amid the COVID-19 pandemic using satellite observations. Environ. Res. 2021, 193, 110514. [CrossRef] [PubMed]

26. Ibrahim, S.; Landa, M.; Pešek, O.; Pavelka, K.; Halounova, L. Space-Time Machine Learning Models to Analyze COVID-19 Pandemic Lockdown Effects on Aerosol Optical Depth over Europe. Remote Sens. 2021, 13, 3027. [CrossRef]

27. Perrone, M.R.; Becagli, S.; Garcia Orza, J.A.; Vecchi, R.; Dinoi, A.; Udisti, R.; Cabello, M. The impact of long-range-transport on PM1 and PM2.5 at a Central Mediterranean site. Atmos. Environ. 2013, 71, 176-186. [CrossRef]

28. Perrone, M.R.; Romano, S.; Garcia Orza, J.A. Columnar and ground-level aerosol optical properties: Sensitivity to the transboundary pollution, daily and weekly patterns, and relationships. Environ. Sci. Pollut. Res. 2015, 22, 16570-16589. [CrossRef]

29. Perrone, M.R.; Romano, S.; Orza, J.A.G. Particle optical properties at a Central Mediterranean site: Impact of advection routes and local meteorology. Atmos. Res. 2014, 145, 152-167. [CrossRef]

30. Romano, S.; Perrone, M.R.; Pavese, G.; Esposito, F.; Calvello, M. Optical properties of PM2.5 particles: Results from a monitoring campaign in southeastern Italy. Atmos. Environ. 2019, 203, 35-47. [CrossRef]

31. Sicard, P.; De Marco, A.; Agathokleous, E.; Feng, Z.; Xu, X.; Paoletti, E.; Rodriguez, J.J.D.; Calatayud, V. Amplified ozone pollution in cities during the COVID-19 lockdown. Sci. Total Environ. 2020, 735, 139542. [CrossRef]

32. Wetchayont, P.; Hayasaka, T.; Khatri, P. Air Quality Improvement during COVID-19 Lockdown in Bangkok Metropolitan, Thailand: Effect of the Long-range Transport of Air Pollutants. Aerosol Air Qual. Res. 2021, 21, 200662. [CrossRef]

33. Brankov, E.; Trivikrama Rao, S.; Steven Porter, P. A trajectory-clustering-correlation methodology for examining the long-range transport of air pollutants. Atmos. Environ. 1998, 32, 1525-2534. [CrossRef]

34. Dinno, A. Nonparametric Pairwise Multiple Comparisons in Independent Groups using Dunn's Test. The Stata Journal 2015, 15, 292-300. [CrossRef]

35. Tiwari, S.; Thomas, A.; Rao, P.; Chate, D.M.; Soni, V.K.; Singh, S.; Ghude, S.D.; Singh, D.; Hopke, P.K. Pollution concentrations in Delhi India during winter 2015-16: A case study of an odd-even vehicle strategy. Atmos. Pollut. Res. 2018, 9, 1137-1145. [CrossRef]

36. Holben, B.N.; Eck, T.F.; Slutsker, I.; Tanrè, D.; Buis, J.P.; Setzer, A.; Vermote, E.; Reagan, J.A.; Kaufman, Y.J.; Nakajima, T.; et al. AERONET-A Federated Instrument Network and Data Archive for Aerosol Characterization. Remote Sens. Environ. 1998, 66, 1-16. [CrossRef]

37. Mallet, M.; Dubovik, O.; Nabat, P.; Dulac, F.; Kahn, R.; Sciare, J.; Paronis, D.; Léon, J.F. Absorption properties of Mediterranean aerosols obtained from multi-year ground-based remote sensing observations. Atmos. Chem. Phys. 2013, 13, 9195-9210. [CrossRef]

38. Schuster, G.L.; Dubovik, O.; Holben, B.N. Ångström exponent and bimodal aerosol size distributions. J. Geophys. Res. 2006, 111, D07207. [CrossRef]

39. Kaufman, J.Y. Aerosol optical thickness and atmospheric path radiance. JGR Atmos. 1993, 98, 2677-2692. [CrossRef]

40. O’Neill, M.S.; Jerrett, M.; Kawachi, I.; Levy, J.I.; Cohen, A.J.; Gouveia, N.; Wilkinson, P.; Fletcher, T.; Cifuentes, L.; Schwartz, J. Health, wealth, and air pollution: Advancing theory and methods. Environ. Health Perspect. 2003, 111, 1861-1870. [CrossRef]

41. Perrone, M.R.; Burlizzi, P. Methodologies to obtain aerosol property profiles from three-wavelength elastic lidar signals. Int. J. Remote Sens. 2015, 36, 4748-4773. [CrossRef]

42. Perrone, M.R.; Burlizzi, P. Mediterranean aerosol typing by integrating three-wavelength lidar and sun photometer measurements. Environ. Sci. Pollut. Res. 2016, 23, 14123-14146. [CrossRef] [PubMed]

43. Seinfeld, J.H.; Pandis, S.N. Atmospheric Chemistry and Physics: From Air Pollution to Climate Change; J. Wiley \&Sons, INC: Hoboken, NJ, USA, 1998.

44. Rodríguez, S.; Van Dingenen, R.; Putaud, J.-P.; Dell'Acqua, A.; Pey, J.; Querol, X.; Alastuey, A.; Chenery, S.; Ho, K.-F.; Harrison, R.; et al. A study on the relationship between mass concentrations, chemistry and number size distribution of urban fine aerosols in Milan, Barcelona and London. Atmos. Chem. Phys. 2007, 7, 2217-2232. [CrossRef]

45. Martins, L.D.; Martins, J.A.; Freitas, E.D.; Mazzoli, C.R.; Gonçalves, F.L.T.; Ynoue, R.Y.; Hallak, R.; Albuquerque, T.T.A.; Andrade, M.d.F. Potential healthimpact of ultrafine particles under clean and polluted urban atmospheric conditions: A model-based study. Air Qual. Atmos. Health 2010, 3, 29-39. [CrossRef] [PubMed]

46. Monteiro dos Santos, D.; Varanda Rizzo, L.; Carbone, S.; Schlag, P.; Artaxo, P. Physical and chemical properties of urban aerosols in São Paulo, Brazil: Links between composition and size distribution of submicron particles. Atmos. Chem. Phys. 2021, 21, 8761-8773. [CrossRef]

47. Sannino, A.; D’Emilio, M.; Castellano, P.; Amoruso, S.; Boselli, A. Analysis of Air Quality during the COVID-19 Pandemic Lockdown in Naples (Italy). Aerosol Air Qual. Res. 2021, 21, 200381. [CrossRef]

48. Shukla, N.; Sharma, G.K.; Baruah, P.; Shukla, V.K.; Gargava, P. Impact of Shutdown due to COVID-19 Pandemic on Aerosol Characteristics in Kanpur, India. J. Health Pollut. 2020, 10. [CrossRef]

49. Perrone, M.R.; Vecchi, R.; Romano, S.; Becagli, S.; Traversi, R.; Paladini, F. Weekly cycle assessment of PM mass concentrations and sources, and impacts on temperature and wind speed in Southern Italy. Atmos. Res. 2019, 218, 129-144. [CrossRef]

50. Romano, S.; Vecchi, R.; Perrone, M.R. Intensive optical parameters of pollution sources identified by the positive matrix factorization technique. Atmos. Res. 2020, 244, 105029. [CrossRef] 
51. Dubovik, O.; Smirnov, A.; Holben, B.N.; King, M.D.; Kaufman, Y.J.; Eck, T.F.; Slutsker, I. Accuracy assessments of aerosol optical properties retrieved from Aerosol Robotic Network (AERONET) Sun and sky radiance measurements. J. Geophys. Res. 2000, 105, 9791-9806. [CrossRef]

52. Santese, M.; De Tomasi, F.; Perrone, M.R. Advection patterns and aerosol optical and microphysical properties by AERONET over south-east Italy in the central Mediterranean. Atmos. Chem. Phys. 2008, 8, 1881-1896. [CrossRef]

53. Dubovik, O.; Holben, B.; Eck, T.F.; Smirnov, A.; Kaufman, Y.J.; King, M.D.; Tanré, D.; Slutsker, I. Variability of Absorption and Optical Properties of Key Aerosol Types Observed in Worldwide Locations. J. Atmos. Sci. 2002, 59, 590-608. [CrossRef]

54. Collivignarelli, M.C.; Abbà, A.; Bertanza, G.; Pedrazzani, R.; Ricciardi, P.; Carnevale Miino, M. Lockdown for COVID-2019 in Milan: What are the effects on air quality? Sci. Total Environ. 2020, 732, 139280. [CrossRef] [PubMed]

55. Grivas, G.; Athanasopoulou, E.; Kakouri, A.; Bailey, J.; Liakakou, E.; Stavroulas, I.; Kalkavouras, P.; Bougiatioti, A.; Kaskaoutis, D.; Ramonet, M.; et al. Integrating in situ Measurements and City Scale Modelling to Assess the COVID-19 Lockdown Effects on Emissions and Air Quality in Athens, Greece. Atmosphere 2020, 11, 1174. [CrossRef]

56. Tobías, A.; Carnerero, C.; Reche, C.; Massagué, J.; Via, M.; Minguillón, M.C.; Alastuey, A.; Querol, X. Changes in air quality during the lockdown in Barcelona (Spain) one month into the SARS-CoV-2 epidemic. Sci. Total Environ. 2020, 726, 138540. [CrossRef]

57. Hashim, B.M.; Al-Naseri, S.K.; Al-Maliki, A.; Al-Ansari, N. Impact of COVID-19 lockdown on $\mathrm{NO}_{2}, \mathrm{O}_{3}, \mathrm{PM}_{2.5}$ and PM10 concentrations and assessing air quality changes in Baghdad, Iraq. Sci. Total Environ. 2021, 754, 141978. [CrossRef]

58. Munir, S.; Coskuner, G.; Jassim, M.S.; Aina, Y.A.; Ali, A.; Mayfield, M. Changes in Air Quality Associated with Mobility Trends and Meteorological Conditions during COVID-19 Lockdown in Northern England, UK. Atmosphere 2021, 12, 504. [CrossRef]

59. Paciorek, C.J.; Yanosky, J.D.; Puett, R.C.; Laden, F.; Suh, H.H. Practical large-scale spatio-temporal modeling of particulate matter concentrations. Ann. Appl. Stat. 2009, 3, 370-397. [CrossRef]

60. INEMAR. INEMAR (AIR Emissions Inventory) (in Italian) 2017. Arpa Lomb. Available online: http://www.inemar.eu/xwiki/ $\mathrm{bin} /$ view/Inemar/WebHome (accessed on 10 October 2021).

61. Hassler, B.; McDonald, B.C.; Frost, G.J.; Borbon, A.; Carslaw, D.C.; Civerolo, K.; Granier, C.; Monks, P.S.; Monks, S.; Parrish, D.D.; et al. Analysis of Long-Term Observations of NOx and CO in Megacities and Application to Constraining Emissions Inventories. Geophys. Res. Lett. 2016, 43, 9920. [CrossRef]

62. Lama, S.; Houwelling, S.; Boersma, K.F.; Eskes, H.; Aben, I.; van der Gon, H.A.C.D.; Krol, M.C.; Dolman, H.; Borsdorff, T.; Lorente, A. Quantifying burning efficiency in megacities using the NO2/CO ratio from the Tropospheric Monitoring Instrument (TROPOMI). Atmos. Chem. Phys. 2020, 20, 10295-10310. [CrossRef]

63. Teixidó, O.; Tobías, A.; Massagué, J.; Mohamed, R.; Ekaabi, R.; Hamed, H.I.; Perry, R.; Querol, X.; Al Hosani, S. The influence of COVID-19 preventive measures on the air quality in Abu Dhabi (United Arab Emirates). Air Qual. Atmos. Health 2021, 14, 1071-1079. [CrossRef] [PubMed]

64. Xu, K.; Cui, K.; Young, L.-H.; Hsieh, Y.-K.; Wang, Y.-F.; Zhang, J.; Wan, S. Impact of the COVID-19 Event on Air Quality in Central China. Aerosol Air Qual. Res. 2020, 20, 915-929. [CrossRef]

65. Nakada, L.Y.K.; Urban, R.C. COVID-19 pandemic: Impacts on the air quality during the partial lockdown in São Paulo state, Brazil. Sci. Total Environ. 2020, 730, 13908. [CrossRef] [PubMed] 